Florida International University

FIU Digital Commons

FIU Electronic Theses and Dissertations

University Graduate School

$12-7-1999$

\title{
Design and implementation of a web based shop floor control system to maintain schedule feasibility in a dynamic job shop environment
}

Anil Bommakanti

Florida International University

DOI: $10.25148 /$ etd.FI14051186

Follow this and additional works at: https://digitalcommons.fiu.edu/etd

Part of the Computer Engineering Commons

\section{Recommended Citation}

Bommakanti, Anil, "Design and implementation of a web based shop floor control system to maintain schedule feasibility in a dynamic job shop environment" (1999). FIU Electronic Theses and Dissertations. 1718.

https://digitalcommons.fiu.edu/etd/1718 
FLORDDA NTERNATIONAL UNIVERSTTY

Miami, Florida

DESIGN AND IMPLEMENTATION OF A WEB BASED SHOP FLOOR CONTROL SYSTEM TO MANTAIN SCHEDULE FEASIBILTY IN A DYNAMIC JOB SHOP ENVIRONMENT

A thesis submitted in partial fulfillment of the

requirements for the degree of

MASTER OF SCIENCE

in

INDUSTRIAL ENGIEERING

by

Anil Bommakanti

1999 
To: Dean Gordon Hopkins

College of Engineering and Applied Sciences

This thesis, written by Anil Bommakanti, and entitled Design and Implementation of a web based shop floor control system to maintain schedule feasibility in a dynamic job shop environment, having been approved in respect to style and intellectual content, is referred to for your judgement.

We have read this thesis and recommend that it be approved.

Dr. Ronald Giachetti

Dr. Shih-Ming Lee

Dr. Chin-Sheng Chen, Major Professor

Date of Defense: December 7, 1999

The thesis of Anil Bommakanti is approved.

Dean Gordon Hopkins

College of Engineering and Applied Sciences

Dean Richard L. Campbell

Division of Graduate Studies

Florida intermational University, 1999 
(C) Copyright 1999 by Anil Bommakanti

All rights reserved. 


\section{DEDICATION}

I dedicate this thesis to my parents, sister, and brother. Without their encouragement, constant support and love, this work would not have been possible. 


\section{ACKNOWLEDGMENTS}

I wish to express my sincerest gratitude and thank the following persons. Without their wholehearted cooperation and constant encouragement this work would never have been completed. My major professor, Dr.Chen.. Thank you, not just for guiding me through the research, but for the constant challenges that you threw at me, encouraging me to do better all the time. Dr. Tang and Mr. Meng, for their understanding and cooperation in helping me with the research and for doing such a wonderful job with the programming. My committee members, Dr. Ronald Giachetti and Dr. Shih-Ming Lee for their support and guidance throughout my research. Dr. Martha Centeno for all the times she guided me throughout my graduation. To my colleagues from the IE department Pablo and Eliecer, I would never have completed this work without you. To my colleagues at work, Man, Jose and especially Leo, for being flexible with my work schedule so that I could concentrate more on my thesis. To all my friends Madhu, Uttam, Prashant, SriAnil, Nikhil, Suresh, Sharad and Keshav, Thank you everyone... from the bottom of my heart. 


\section{ABSTRACT OF THE THESIS \\ DESIGN AND MPLEMENTATION OF A WEB BASED SHOP FLOOR CONTROL \\ SYSTEM TO MAINTAIN SCHEDULE FEASIBILTY IN A DYNAMIC JOB SHOP \\ ENVIRONMENT}

by

Anil Bommakanti

Florida International University

Professor Chin-Sheng Chen, Major Professor

The effective control of production activities in dynamic job shop with predetermined resource allocation for all the jobs entering the system is a unique manufacturing environment, which exists in the manufacturing industry. In this thesis a framework for an Internet based real time shop floor control system for such a dynamic job shop environment is introduced. The system ams to maintain the schedule feasibility of all the jobs entering the manufacturing system under any circumstance. The system is capable of deciding how often the manufacturing activities should be monitored to check for control decisions that need to be taken on the shop floor. The system will provide the decision maker real time notification to enable him to generate feasible altemate solutions in case a disturbance occurs on the shop floor. The control system is also capable of providing the customer with real time access to the status of the jobs on the shop floor. The communication between the controller, the user and the customer is through web based user friendly GUI. The proposed control system architecture and the interface for the communication system have been designed, developed and implemented. 


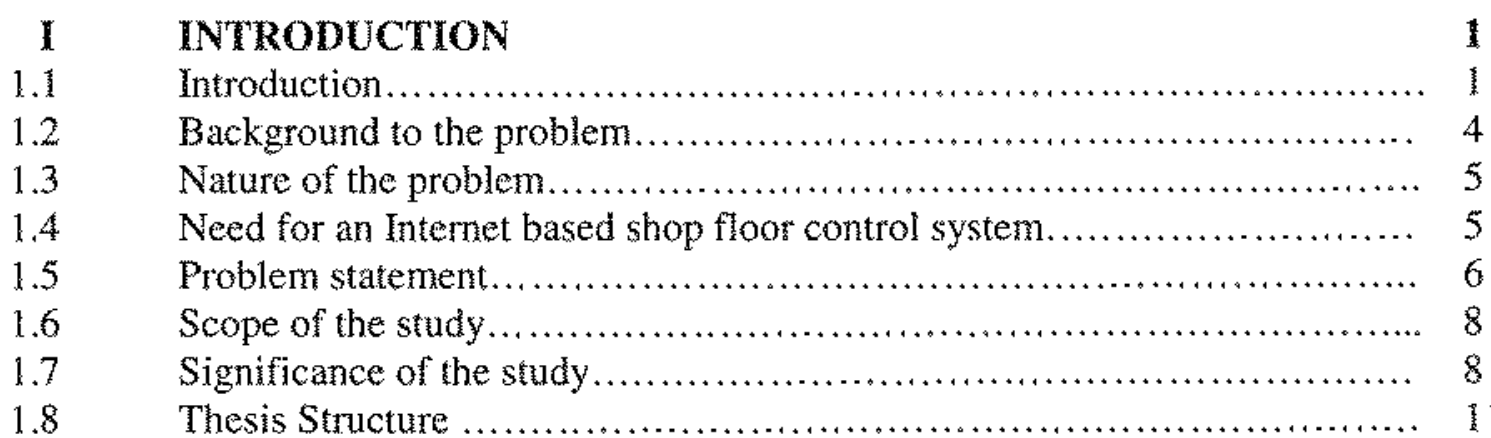

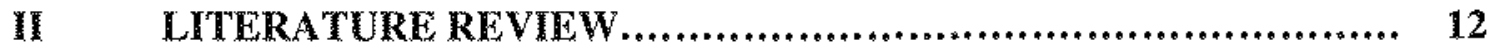

$2.1 \quad$ Characteristics of Control Systems ................................... 12

2.2 Order release mechanisms in job shops............................... 14

2.3 Shop floor control system architectures.............................. 17

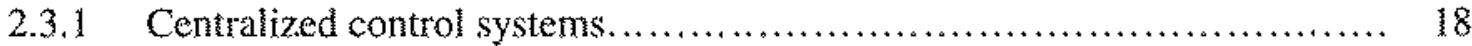

2.3.2 Hierarchical control systems.......................................... 19

2.3.3 Modified Hierarchical control systems.................................. 20

2.4 Heterarchical (Distributed or Autonomous) control systems............... 21

2.4.1 Control algorithms in SFCS - Data collection and Decision making........ 22

2.4.2 Decision making process in existing SFCS............................ 23

2.5 Implementation issues in SFCS................................... 25

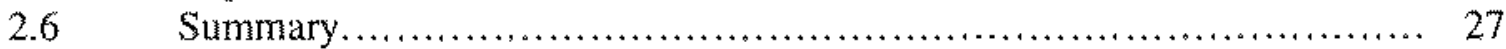

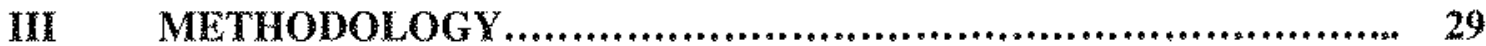

3.1 Manufacturing operations system environment ........................... 29

3.2 Shop Floor Control System ........................................ 30

$3.3 \quad$ Control System Architecture ...................................... 32

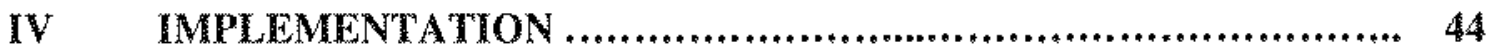

4.1 Manufacturing operations environment ............................... 44

4.2 Manufacturing operations system environment........................... 45

$4.3 \quad$ Implementation environment...................................... 46

4.4 Shop floor control system architecture .............................. 47

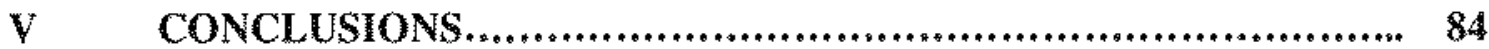

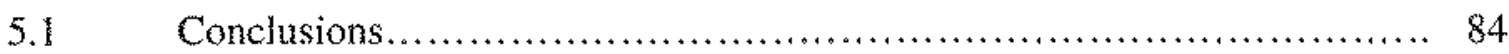

$5.2 \quad$ Future research........................................................ 86

References........................................................... 88 


\section{LIST OF FIGURES}

FIGURE

la Shop floor control system......................... 36

lb Report of fact from user............................... 40

lc Correction of prior event ............................. 42

2 Architecture of the manufacturing operation system....... 46

3 Shop floor control system............................. 46

$4 \quad$ Specialist menu options.............................. 48

$5 \quad$ Specialist Log on Form............................. 49

$6 \quad$ View job list/machine breakdown options................ 5 I

$7 \quad$ Machine recovery $/$ Worker absence options............... 52

$8 \quad$ Worker return option................................... 53

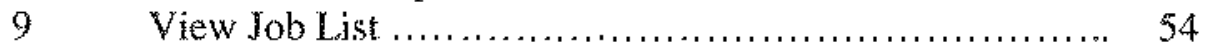

10 Report Machine Breakdown .......................... 55

11 Report Machine Recovery ............................ 56

12 Report Worker Absence ............................ 57

13 Report Specialist Return ............................ 58

14 Outsourcing system algorithm........................ 59

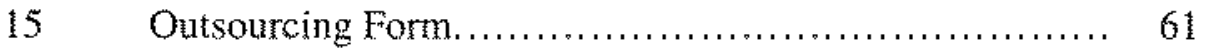

16 View/Edit Existing Orders Form...................... 63

$17 \mathrm{a}$ Shop floor control system algorithm................... 65

$17 \mathrm{~b}$ Shop floor control system algorthm................... 66

18 Shop Floor Control Form............................ 67

19 View Job Orders In SFCS Form..................... 68

20 View Job Orders In Shop Floor control System Form...... 73

21 View Jobs Impacted by Start Delay Form................ 74

22 View Jobs Impacted by Finish Delay Form............... 75

23 View Jobs Impacted by Machine Breakdown Form........ 77

$24 \quad V i e w$ Jobs Impacted by Specialist Absence Form........... 78

25 View Jobs Impacted by Outsourcing Delay Form.......... 80

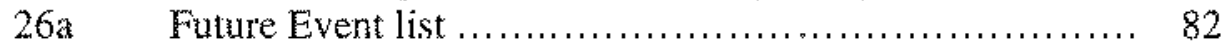

26b Future outsource arrival list......................... 83 


\section{Chapter One: INTRODUCTION}

\subsection{Introduction}

In the current global business environment, fierce competition is forcing organizations to rapidly change strategies in order to adapt to the constantly changing environment. In order to be successful, organizations have to possess the ability to thrive in a competitive environment with continuous and unanticipated change, respond quickly to rapidly changing, fragmenting and globalizing markets which are driven by demands for high quality, high performance, low cost customer-oriented products and services. Such competition often pressurizes organizations to be lean and agile. This has led to organizations often relocating the manufacturing facilities to places where the production costs are much lower, giving rise to geographically distributed organizations. One of the prerequisites for such an organization to be competitive, is the availability of information - accurate, complete, on time, interpretable data, from all the manufacturing facilities for the management to be able to make quick decisions. On the other hand, many organizations are also entering into business dealings with manufacturing facilities that are physically removed from the place they are in. Geographic location is no longer a factor in deciding whom to do business with. Cost, quality and on time delivery are the driving factors in today's business scenario.

A manufacturing plant may be viewed as a system with much input and usually only one relevant output - the final product. Marufacturing a product from a design on shop floor involves three major activities: creating a set of manufacturing instructions and a production schedule, fitting the instructions and schedule to some objective(s) in 
response to dynamically varying shop foor environments, and manufacturing the part according to the instructions. In terms of discrete production systems, these three activities are usually called process planning, production control and manufacturing. However in any manufacturing facility there are frequent changes in the operating system environment, such as machine failures or tool shortages and process requirement variations, which affect the smooth and efficient functioning of the system. The performance of the manufacturing facility hinges on its ability to rapidly adapt its production schedule to such internal and other external disturbances to the manufacturing environment. This includes the ability of the manufacturing system to aler the user to take early actions whenever there is a disturbance in the system and the customer"s jobs might get delayed beyond the scheduled delivery dates.

In a dynamic job shop, a Shop floor control system (SFCS) is concerned with a group of activities required to convert orders released to the shop floor by the planning system into a set of completed orders which conform to the requirements of the planning system in an efficient and cost effective manner. The shop floor control system consists of production control and actual manufacturing that are performed in parallel. The control system is responsible for the physical flow and information flow in the shop floor environment. Process plaming (at least the initial process planning) and scheduling are done off line, prior to on-line shop floor control. Process planning may be considered as a mapping; where its domain is the product design data and its range is the process plan, which is the shop floor control system's domain. Scheduling is the allocation of available shop floor resources (labor, machines, materials/tools) to the production process, to 
ensure that the manufacturing constraints are met and the part is processed as per the design specifications

In the context of discrete part manufacturing, a typical process plan includes machining operations and their sequence, resource requirements, machining parameters, jigs/fixures, setup instructions, and auxiliary descriptions. Each manufacturing order comes to the shop floor with a schedule, which is prepared according to estimated tool/material arrival times, processing times, and the timely completion of each existing job schedule on the shop floor. Each new job is released to the shop floor immediately after being scheduled. The control system interfaces the upper level planning and scheduling modules, low level device control modules, and various other control modules such as warehouse control and inventory control to carry out part and resources assignment. The control system must be capable of responding to the changes and failures of these components, and also respond to external disturbances such as order variations, vendor changes, and product design changes and accommodate these multiple changing criteria with respect to the cost, quality, time and system flexibility.

In order to be able to accomplish the above objectives, the shop floor control activity must endeavor to maintain the schedule that is originally sent to the floor for manufacturing activities. This means there has to be a control system which has complete control over the manufacturing environment and can keep track of each job task.'s schedule and alarm the controller for any delay or forecasted delay, thus permitting remedial actions to be taken at the time the delay occurs or is predicted. This is particularly important in dynamic job shops where there is no inventory and the lead-time is tight, furthermore, there are constant changes in the system. 


\subsection{Background of the prohlem}

In all manufacturing systems jobs get delayed when disturbances occur in the system often resulting in the manufacturer defaulting on the scheduled delivery date, thus potentially leading to loss of future orders from customers and consequently resulting in reduced competency. The ability of a control system to track individual jobs at every instant in the system can potentially prevent them from getting delayed when a disturbance occurs in the system. This becomes possible by identifying the affected jobs on time and rescheduling or rerouting them to the relevant resources (if available) or the management can take appropriate decisions on whether or not the job should continue being processed in the system or be outsourced, to avoid getting delayed. This decision may also help to identify and release any additional jobs that may exist in the pre order pool, to the shop floor to maximize the utilization of resources.

For a manufacturing system to have such a high degree of responsiveness, it requires detailed information on all the operational aspects of the manufacturing activities. Current manufacturing systems lack the ability and the technology to continuously track all the jobs in the manufacturing process on a real time basis; though they can track total cycle time of the jobs in the system. This often results in resources being wasted on orders that are eventually canceled, remedial measures not being taken early enough, or customers not being informed ahead of time to modify their plans according to the delay or estimated delay in the expected due date of the jobs.

Over the past decade, particularly in the last few years, there have been tremendous breakthroughs in the information technology systems field, which have a very wide application in the manufacturing industry. The rapid development of the Internet 
technology has revolutionized the way business is conducted. The effective use and implementation of this technology now permits the online control of manufacturing systems on a real time and continuous basis.

\subsection{Nature of the problem}

This effort is aimed at studying the control system in a dynamic job shop environment. There exist numerous procedures, heuristics and algorithms existing in current literature, which can control the manufacturing activities in such an environment. This study attempts to develop the architecture of a shop floor control system, which uses the Internet as a data collection and communication tool to maintain and perform the control process for the production activities scheduled to take place on the shop floor, in such a manner that the schedule feasibility (completion of the job operations as per scheduled due date) of the jobs on the shop floor is maintained in spite of any disturbances occurring in the system.

\subsection{Need for an Internet based shop floor control system}

In the current basiness environment ensuring ontime delivery of jobs is a prerequisite to remain competent. When there are unforeseen delays, this information must be relayed immediately to the customer so that they can take remedial measures in accordance with the estimated delay. This rapid exchange of this information is crucial as in many cases the manufacturing facility; management and the customer are geographically separated. The effective management and control of this information has

now become an essential prerequisite to the survival of many organizations. Traditional 
shop floor control methods, though capable of controlling the shop floor environment, are often found lacking in relaying the shop floor information to the controller and other relevant decision making personnel including the customers, in real time. Use of the Intemet as a communication tool in such scenarios can help in collecting, processing, analyzing and relaying online, the information from the shop floor, and hasten the decision making process based on the information exchanged

\subsection{Problem statement}

The problem discussed in this study is the design and implementation of a shop floor control system, which maintains the schedule feasibility in a dynamic job shop. The resources performing each of the operations are specified in the schedule. The starting and ending times of each operation and the job due dates are also known to the controller before the production activity begins. The jobs are released to the system as soon as they are scheduled, and the jobs are dispatched in to the system at the instant when their first operation is scheduled to start. Therefore there is no conflict of resources and the jobs are not competing with each other on the shop floor.

In spite of the system environment being controlled to such a large degree, there still exists a possibility that the schedule can be delayed in case certain disturbances occur in the system. In order to maintain the sanctity of the due dates for the jobs and also maintain the feasibility of each of the job schedules, it is important to have a control system that maintains a constant check on the system and provides feasible alternatives to resolve the disturbances arising on the shop floor in real time. The control system should provide the framework to collect data from the shop floor, facilitate the analysis of the 
available options, and provide solutions or facilitate decision making on the data received from the shop floor. The study aims to accomplish the following,

1. The shop floor control system architecture will be designed in such a way as to,

* Provide an integrated environment on the Internet, to evaluate feasible altemate control policies.

- Perform supervisory control of all the shop floor activities in real time.

- Determine when and how often shop floor activities are to be monitored and evaluated, also to identify automatically when and where control actions must be taken for various critical events.

* Respond to disturbances on the shop floor activities by allocating equivalent alternate resources for completion of the job or initiating a search for alternate solutions in such a way that the job is completed on schedule.

- Provide qualitative reasoning on the various options and decistons available.

- Possess a look-ahead capability to avoid potential disturbances in the system.

- Capture and correct the erroneous and incorrect information received from the shop floor in a timely manner and evaluate the impact of such errors.

- Facilitate in the generation a computer model of the shop floor activities for the purpose of analyzing different control policies off-line by the controller.

- Potentially offer capabilities to learn and adapt to changes in the manufacturing system.

2. The communication interface between the users, the controller and the other dectsion making authorities will be developed so as to,

- Provide feedback to the customer in case a job is going to be delayed 
- Facilitate data and information exchange between the shop floor, the contraller and the customer on a real time basis through the Intenet.

\subsection{Scope of the study}

The study is limited to a dynamic job shop environment. Each job released for manufacture on the shop floor has a fixed schedule and a predetermined route specified in the process plan. At the manufacturing execution stage, there are no alternatives made available to the job, either in terms of machines or workers. If a job is scheduled on a particular work center and worker, then it waits for the resource to become available. The job can however be allocated to alternate resources at the process planning stage or alternate resources (similar machines in a work cell, or an equivalent worker) may be specified in the schedule, which can perform the operations in case the scheduled resources become unavailable. The scope of the study includes the following assumptions and constraints:

- The process plan and schedule for each job entering the system are available with the controller.

- Each job entering the system has a feasible schedule. The feasibility of the job schedule is evaluated and confirmed by taking the shop load conditions of the system into consideration at the scheduling stage.

- The communication system between the controller and all the users of the system is already in place.

\subsection{Significance of the study}


In any business transaction, a commitment to provide timely services or products to business partners forms the basis for future business planning. Many related activities are planned and scheduled around that commitment, under the assumption that it will be met. The customer expects the order to be delivered as commited and sclzedules their activities on a similar timescale. In a dynamic job shop environment, when a manufacturer accepts an order, the order completion and delivery date is the commitment made to the customer and all the manufacturing activities related to the order are planned and scheduled in line with it. Unfortunately, due to practical circumstances, often there arise situations when the commitments cannot be met as planned. This invariably leads to losses incurred by either one or both the entities.

The ability of the manufacturer to relay comprehensive information on the status of a job, including the potential delay and the estimated completion time, in case of a delay, to the customer; or the ability of a customer to access relevant information in real time to review the status and plan their activities accordingly (this includes the ability to review the delivery date and bring it ahead or reschedule it to a later date), offers a potential solution to the above problem. If information on the order delivery date can be relayed to the custoner in advance, then there are chances that the degree of the losses incurred (on both sides) can either be reduced or eliminated completely. This necessitates the presence of a smooth and efficient communication channel between the concerned entities.

The relevant information should be exchanged in as close to real time as possible, in order to provide customers the time and opportunity to prepare alternate plans whenever possible, to minimize the losses that may be incurred. This requires a system 
that is capable of constantly monitoring the manufacturing activities, anticipate potential delays by analyzing the shop floor activities on line, facilitate decision making on the job stafus by estimating future completion dates, and transfer this qualitative data to the concerned customer in a very short period of time. The existing manufacturing systems and communication channels for data transfer are not completely equipped to meet this challenge, which means, in the past even when manufacturers knew in advance that the order would be delayed, the relevant information could not be passed on to the customer in time.

The technological advances made over the last decade in the field of information technologies, have opened up channels of communication that has introduced a new paradigm in the manner business is conducted globally. The widespread use of the Intemet technologies have drastically reduced the cycle time for many business transactions. Competition has increased manifold and instant access to information has opened up new avenues for business applications and has transformed organizational structures. Large amounts of data and information can easily be downloaded or transmitted to any other part of the world in minutes. In order to remain competitive today, an organization needs to access information in the shortest possible time.

In the manufacturing industry, access to information regarding an outsourced job's delivery status is a crucial link to the overall planning process of the business activity. At the same time, for a manufacturer to remain competent, it is imperative to fulfill the order delivery commitments under all circumstances. If for some unforeseen circumstances an order is going to be delayed, then it becomes necessary to inform the customer of the delay in the shortest possible time and attempt to achieve the next best 
solution acceptable to them. This arms the customer with advance information of the delay and presents the opportunity to reschedule critical activities as required. The customer can then inform the manufacturer whether the estimated delay is within acceptable limits and the manufacturer should continue processing the job. If not, the customer can look for altemate sources, which will satisfy their requirements.

\subsection{Thesis Structure}

In Chapter II, the relevant research has been reviewed; Chapter III discusses the methodology and the system design; Chapter IV discusses the implementation of the proposed system. 


\section{Chapter Two: LITERATURE REVIEW}

This chapter reviews the research related to shop floor control, particularly problems related to shop floor loading, the different control architectures and algorithms proposed to maintain the smooth and efficient performance of the operational characteristics in a manufacturing environment and the implementation of such a control system to cope with the dynamics of a manufacturing system. Researchers have proposed various types of control systerns to ensure and improve system performance. The first section of the chapter summarizes the characteristics of control systems reviewed. The following sections review the order release mechanisms in job shops, the various shop floor control system architectures, and the implementation issues in shop floor control systems.

\section{1 Characteristics of Control Systems.}

Andersson (1997) describes an approach to integrate applications for the various components of the control system, such that the manufacturing system is able to convert data into useful information and in turn distribute it, regardless of the vatiations in the different application module architectures developed by different programmers. Aguirre et al (1999) present an architecture for manufacturing control systems based on a unification of standards for distributed architecture. The architecture is designed primarily to structure and support generalized manufacturing control system implementation. 
An important part of the control system is the architecture that describes the subparts of the shop floor control system, what they do, how they interact between themselves and with the users of the system. Mannivan and Banks (1992), Maglica (1997) and Lin and Solberg (1992) report that a shop floor control system should incorporate as many of the following characteristics as possible:

- Divisible into a number of well-defined functions: To facilitate modular implementation of the SFC system, the architecture should consist of a number of entities, each performing only one function.

- Able to separate the specific from the generic: It is important that the architecture allows the separation of parts that are specific for a particular manufacturing systen from those parts that are generic for all manufacturing systems.

- Adapted to its working environment, the shop floor: The architecture should use a structure and terminology that makes sense in the domain, the shop floor. Failure to do this will probably degrade the performance of the manufacturing system.

- Integrated control: An integrated framework is needed to utilize system resources effectively. Subsystem optimization such as part-machine scheduling, isolated tool management, isolated transported control can cause system under-performance. Availability of different resources should be considered in decision-making and the most critical resource should have the greatest impact in decision-making. The architecture must support integration of shop floor activities between and within levels of the control hierarchy.

- Networking and data communication: The ability of the control system to be able to perform the following functions 
i. Ability to transfer data with high integrity

ii. Quick response

iii. Continuous operation

iv. Ability to handle network errors

v. Protocol conversion

vi. Network reliability

vii. User support and software maintenance

- Efficiency: The system needs to utilize resources well to satisfy the needs of the customer.

- Robustness: The factory must be able to continue operating despite unexpected events.

- Simplicity: A simple architecture is easier to understand and to apply.

\subsection{Order release mechanisms in job shops}

The order release and job dispatching rules problem has been studied by several researchers over a period of time, as illustrated by Bergamaschi et al (1997), Ragatz and Mabert (1988), Melynk and Ragatz (1989), Blackstone et al (1982). Order release and dispatch mechanisms are the starting points in shop floor control and includes those activities, which must take place before an order defined by a planning system, can be released to an execution system. These activities are necessary to control the flow of information and orders passing from the planning system to the execution system and to ensure that the orders released have a reasonable chance of being completed by the time and in the quantity required. 
In dynamic job shops, the order release mechanism is of particular importance to measure the effectiveness of the system performance. In existing literature, the effectiveness of the system is determined by various measures of performance like total operating cost (Phillipoom et al., 1993; Ahmed and Fisher, 1992; Ragatz and Mabert, 1988), system/machine utilization (Ragatz and Mabert, 1988; Chang, 1997) flow time (throughput), tardiness and its related measures (Holthaus and Rajendran, 1997; Bertrand J.W.M., 1983; Ahmed and Fisher, 1992). These measures of performance depend on the order release and job dispatching rules governing the system. The order release and the job dispatching rules affect the shop load conditions and the workflow characteristics prevailing in the system. Since the workflow characteristics and the load conditions on the shop floor are functions of the job characteristics, they affect the tardiness of the system. Several researchers have studied the work load conditions and dispatch rules prevailing in the system by measuring the system tardiness and suggest controlling the tardiness related measures under various due date tightness by regulating the jobs entering the system to reduce the operating cost, thereby improving the performance of the system.

Melynk and Ragatz (1989) identify that the interaction between the due date tightness and the dispatching rule is significant only for tardiness related measures. Bertrand (1983) investigates how the due date performance of job shops improves when due dates are based on order characteristics as well as on the workload condition in the shop. Land and Gaalman (1998) in their research suggest an alternative approach to those order release methods that result in deteriorated lead-time and due date performance by controlling the workload in a balanced job shop instead. 
Ragatz and Mabert (1988) in their study of order release mechanisms identify that controlling order release may not reduce the total time an order spends in the system though it can improve the system performance criteria of total shop cost, by reducing the variability of the shop load and influencing where the job spends its time in the system. Phillipoom et al (1993) study the effect of an intelligent capacity based order release mechanism and two job dispatching rules, under various due date tightness conditions on the cost performance of the manufacturing system.

Ahmed and Fisher (1992) investigate the effects of the interactions between a combination of due date assignment, the order release and sequencing procedures over different shop utilization levels on the total cost of a job shop system. Holthaus and Rajendran (1997) in their excellent research, study the effect of he dispatching rules, some of which account for the shop load conditions and the job processing time, on the flow time and tardiness related measures of performance of a job shop.

Perona and Portioli (1998) in their unique research investigate the performance of an order release mechanism that controls the release of orders into the system based on the load capacity at each work center in the system, by varying different parameter settings for a specified planning period.

Chang (1997) studies factors that have a significant effect on the prediction capabilities of due date assignment rules on jobs entering a dynamic job shop environment, and the relative effects of these factors on the completion times of the jobs under various dispatching rules and shop utilization levels.

There have been attenpts to introduce the current information technology systems towards improving the efforts described in the literature review. Yurtsever and Pierce 
(1998) describe a real time graphical manufacturing and monitoring system capable of generating various job dispatch rules online, for order release in a job shop. Tatsiopoulos (1997) defines architecture for the order release process while developing an order release reference model.

The above efforts are directed towards enhancing the shop performance by reducing tardiness through efficient dispatching rules and improving the workload conditions on the shop floor. There is no real effort to completely eliminate tardiness from the system. However in the current business scenario, the due date is a deadline set by the end user of the job and is often a binding factor, making tardiness no longer acceptable. Though all the order release mechanisms and job dispatch rules reviewed endeavor to reduce job tardiness and tardiness related measures, they do not ensure that the jobs will be completed as per the due date assigned at the process planning stage. The efforts have largely been aimed at improving the system performance, and not towards providing a solution to the problem of maintaining the schedule feasibility.

\subsection{Shop floor control system architectures}

Maglica (1997) defines an architecture as "the structure and design of something; the collection of elements which allow to structure and design something in a consistent way". Zwegers et al (1997) state that the purpose of architecture is to structure a complex system. Smith et al (1996) identify three basic guidelines for developing manufacturing control architectures:

- Levels of control structures should be introduced to reduce the complexity and limit responsibility and authority 
- Each level should have a distinct planning horizon that decreases as one goes down the hierarchy; and

- Control should reside at the lowest possible level.

Lee and Wysk (1995) and Dilts et al (1991)have classified shop floor control systems into four types: centralized control systems, hierarchical control systems, modified hierarchical control systems and heterarchical (or Autonomous) control systems.

\subsubsection{Centralized control systems}

The centralized control architecture is characterized by a mainframe computer that performs all the planning and information processing functions and maintains global databases to record the activities of the whole manufacturing system. Shop level and cell level responsibilities are concentrated in a single location while simple machine controllers are dispersed throughout the manufacturing environment. The machine controllers execute commands received from the centralized control facility. Commands are issued in such a manner as to coordinate the physical manufacturing process. The centralized control unit receives monitoring information from shop floor sensors and machine controllers, which it uses to make global control decisions.

Bongaerts ef al (1997) argue that centralized architectures are no longer effective in today's manufacturing environment. Due to the increasing market demand for flexibility in manufacturing processes, the system should be capable of responding to the system disturbances as early as possible. Besides, centralized control structures are slower to respond as the manufacturing systems get larger and more complex. Further, in centralized architectures if the unit fails, the entire control system (and hence the manufacturing system) can no longer function efficiently. 


\subsubsection{Hierarchical control systems}

This form is characterized by the presence of several layes of control and contains several control modules arranged in a pyramidal structure. These distinct levels have their own purpose and function. The higher (master) level dictates all the activities of the lower (slave) level and the lower levels have no recourse but to conply.

Smith et al (1996) identify three levels of control systems generally referred to in hierarchical manufacturing systems, (i) shop level control systems, (ii) workstation level control systems and (iii) equipment level control systems. The controller in each level of the hierarchy is responsible for decomposing a task, passing the subtasks to the subordinates and monitoring the status of the process. The sequence of passing tasks to the lower levels can be sequential, in parallel or in some combination according to the nature of the task. There are several researchers who have applied the hierarchical structure to develop control systems which make an effort the maintain the schedule developed at the planning stage.

Monostori et al (1998) compare the performance of reactive and proactive approaches in hierarchical control architectures against distributed (heterarchical) control architectures, for disturbances in the manufacturing systems. Hansen et al (1998) and Saleh et al (1991) present control systems, which differentiate between the on line and off line control functions, by performing online rescheduling activities when a disturbance occurs in a work cell and specify the planning activities needed to bring the cell back to the steady state level of performance, offline.

Bilberg and Alting (1991) propose the use of simulation as an effective tool for rescheduling in control systems by identifying alternate solutions in the system. Karacal 
(1998), Belz and Mertens (1996) and Mannivan and Banks (1992) extend the use of simulation in control systems by using knowledge-based techniques to perform rescheduling when a disturbance occurs in the system.

Simulation techniques suggest alternate course of actions when disturbances occur in the system. The control system reacts to disturbances in the system by simulating all the possible scenarios, which provide a feasible alternative to resolve the disturbance. Simulation systems that use knowledge-based techniques, however have a few limitations. One of the drawbacks with such systems is their inability to provide solutions to situations, which are not housed in the knowledge base of the system. Further, in dynamic job shops, which is the scope of this study, most jobs are unique. This might restrict the application of the rules housed in the knowledge base if the manufacturing system has not performed a similar job before.

\subsubsection{Modified hierarchical control systems}

The modified hierarchical form shares many characteristics of the proper hierarchical structure. The main distinction between proper and modified forms lies in the degree of autonomy of subordinates. In this mode, there is minimum communication between the shop level control system and the workstation level control system. The shop level control system's primary function is to start off each job at its first cell and pass enough information to first workstation level control system so that the workstation level can arrange for the job to be transported to its second cell. This first workstation level also has to arrange for enough information to be passed to the subsequent cells to permit the completion of the job, in this way the shop floor level manages by exception, and gets involved only when there is a significant disturbance to the planned activities. 
Zamai et al (1998) introduce a modular hierarchical control system for discrete event manufacturing systems with an inter-level communication mechanism for real time monitoring and control of the system.

\subsection{Heterarchical (Distributed or Autonomous) control systems}

This architecture is based on the philosophy that because of the complexity and uncertainty of manufacturing systems, central decision making is not feasible. Heterarchical control systems operate through cooperative behavior of many interacting subsystems, which may have their own independent interests and modes of operation. This architecture has physically distributed autonomous entities that communicate with each other, without the master/slave relationship of a hierarchical architecture. The cooperation between entities is arranged via a negotiation procedure. The most important character of a two party cooperative protocol is that it allows any resource to refuse the transfer or acceptance of a message based on its own knowledge of its own status.

Kim et al (1997) and Lin and Solberg (1992) describe a negotiation based scheduling algorithm by defining part and resource agents, which act as autonomous bidding and pricing agents in an integrated environment and perform the control system functions for a dynamic and changing manufacturing environment. Tharumarajah and Bemelman (1997) review and compare the presence of distributed entities in both hierarchical and heterarchical architectures for negotiations based control and introduce the concept of behavior based control in manufacturing systems.

Brussel et al (1998) describe a holonic reference architecture for control in manufacturing systems. The architecture presented combines features from both the 
hierarchical and heterarchical control systems by providing the stability of the former and the dynamic flexibility of the latter. Bongaerts et al (1997) advance the holonic manufacturing concepts and introduce a framework for the design of evolutionary control systems. Baker (1998) identifies three control architecture algorithms; dispatching, scheduling, and pull algorithms for heterarchical manufacturing control systems commonly being used in the manufacturing industry today. Boucher and Jafari (1992) design a control system using petri nets. Rovithakis et al (1999) use a dynamic neural network model to develop a real time control system for an FMS.

\subsubsection{Control algorithms in SFCS - Data collection and Decision making}

Decision making at all levels in any SFCS requires access to various types of information while the system is running. This includes accessing information like part process plans, numerical control flles, and machine/worker status reports. Smith et al (1996) identify the possible methods to receive/access data; (i) the controller receives the data from his supervisor as part of the command structure (ii) the controller has his own database management system (iii) the controller must have an interface with the global manufacturing database management system. Mannivan and Banks (1992) state that the efficiency and effectiveness of the data collection in the control system depends upon one or more of the following factors:

i. Freshness of dynamic data: Data can be periodically acquired or can be collected continuously in real time. This decision concerning the frequency of data collection depends upon the complexity of the shop floor and the nature of elapsed time between disturbances. 
ii. Degree of Automation of Data Collection: The dynamic data can be collected using manual operators or the data can be collected using data collection systems connected to computers.

iii. Degree of Reaction to Data from Shop floor: The control system can react to every change in the data or can react to very specific changes received from the shop floor. Reacting to every change in the data can make the system very unstable, whereas failure to react can pass up many opportunities to improve effectiveness and efficiency.

\subsubsection{Decision making process in existing SFCS}

Smith et al (1996) describe decision-making process in a hierarchical control system in which the workstation controller carries out commands received from the shop controller and is responsible for moving parts between different equipment in the workstation, and specifies part processing performed at the equipment. To this end the system synchronizes the actions required for coordinating the transfer of parts between processing equipment and material-handling equipment. Synchronization may also be required between the material handling equipment and a material transport device present at a port to deliver or remove parts. Bilberg and Alting (1991) state that the on-line control of the shop floor activities takes place at the operational level. The term "control" covers control at the operation level - especially direct control. A detailed plan with a shott-tem horizon is generated that determines which parts are going to be produced on the individual machines. Direct control concerns the routing of parts and equipment through the system and takes advantage of the alternatives that exist within the 
framework of the detailed plan. It is the control and synchronization of the physical elements (machines, transporters, storage, parts, pallets, fixtures, tools, etc.).

Karacal (1998) in is research states that the performance of a manufacturing system is highly influenced by control policies used in its operation and that decisions at each level are made using heuristics, personal expertise, company rules and policies. Belz and Mertens (1996) combine knowledge based systems and simulation that model the shop and evaluate the result of various rescheduling measures. The combination of the two systems serves to gather information from the system, configure the simulation experiments, perform analysis, derive conclusions and makes suggestions for promising measures.

Lin \& Solberg (1992) describe a population of intelligent entities in the form of part and resource agents, which operate cooperatively to achieve individual goals instead of machines processing jobs according to a plan established by a global controller. The cooperative system recognizes the fact that very complex systems are beyond direct control. Instead they operate through the cooperative behavior of many interacting subsystems, which may have their own independent interests, values, and modes of operation and the resulting behavior of the entire system is collectively determined. Kim et al (1997) make an effort to improve the performance of such cooperative systems by making the different entities look ahead into the future during the scheduling operations. Brussel et al (1998) make a further advancement to the control system by decoupling the system structure from the control algorithm. They identify three autonomous cooperating holons in their structure, which are capable of constant adaptation and thigh flexibility. 
The above control systems reviewed perform shop floor control on a real time basis, but there is no effort to pass on the advantage of possessing the knowledge of a potential delay in the due date of a job to the customer. The control mechanism is restricted to the shop floor and does not extend the advantages of on-line control beyond its boundaries. Further the control mechanisms discussed, concentrate on correcting the disturbance occurring in the system, the focus is not on maintaining and meeting the job due date. The control systems discussed make an effort to improve the overall performance of the manufacturing system, at either of the two levels

- Improving the shop loading, whereby the various measures of performance such as shop utilization, throughput, overall cost, tardiness and its related measures are monitored and improved upon by using various heuristics, policies and rules governing the jobs released into the system.

- At the second level, the control architectures / algorithms make an effort to improve the performance of the system either proactively or reactively by presenting various solutions to the rescheduling of jobs once a disturbance has occurred in the system.

\subsection{Implementation issues in SFCS}

Little and Yusuf (1997) take an evolutionary view of the developments in manufacturing control systems and classify them chronologically into the following six paradigms: (i) Material requirements planning (MRP), (ii) Manufacturing resource planning (MRPID, (iii) Leitstands and finite schedulers, (iv) Optimized production technology, (v) Just in time manufacturing (JTT), and (vi) Enterprise resource planning (ERP). Kappelhoff (1998) lists the requirements and the environment in organizations in 
which the ERP/MRP systems can be implemented. $\mathrm{Ng}$ and $\mathrm{lp}(1998)$ present an ERP system with a flexible architecture to support real time data collection and processing for all required production and inventory analysis, which can meet the requirements of a distributed business organization.

Wright and Burns (1997) introduce a new dynamic organization paradigm incorporating and affecting organizational technology, people, structure and strategy Virtual green teams, to help better face the challenges presented by an ever changing environment. They discuss Intranet technology, which facilitates communication opportunities at strategic, tactical and operational levels, to increase the efficiency of existing information delivery and to change the business processes leading to increases in overall effectiveness of organizational information delivery.

Hye and Joel (1999) present the characteristics and organizational aspects of a virtual enterprise. They show that organizational and technical issues are closely related and present an innovative Is infrastructure which describes a global network centric support for this kind of inter organizational manufacturing system with the background of modern information and communication technology.

Davis and O'Sullivan (1998) examine and compare four information exchange technologies: Electronic Data Interchange (ED), the Internet, corporate Intranet and GroupWare. Tu (1997) presents the basic concepts and methods, a reference control structure, and a reference company architecture to cope with the problems of production planning and control in a geographically distributed organization.

The above review suggests that the rapid improvements in the information technology have wide applications in the manufacturing environment. Though the efforts 
are leading towards improving the effectiveness of the organization as a whole, there still exists scope for applying these technologies at the operation level of the manufacturing enviromment.

\subsection{Summary}

Manufacturing systems use the shop workload condition and workflow characteristics to control the tardiness of the system, which acts as a yardstick to measure the system performance. The effort to improve the system performance was directed towards achieving a balanced load condition on the shop floor by use of various order release and job dispatching rules under various due date tightness levels. From the literature review presented on the control system archifectures it is seen that the architecture forms the core of the control systems and the decision-making in the system depends almost entirely on the architecture. In existing literature the approach for conducting shop floor control can broadly be divided into (i) the control of the operational characteristics of a manufacturing environment by regulating and monitoring the jobs released into the system, (ii) the control of the operational characteristics of a manufacturing environment, where the jobs have a predetermined process plan but flexible schedules and routes on the shop floor (iii) the control of the operational characteristics of a manufacturing environment that has flexible process plans, job schedules and routes for the jobs entering the shop floor. Based on the review presented the following conclusions can be drawn:

- There exists today, a manufacturing enviromment where the jobs entering the system have a process plan, schedule and all the resources allocated to them before they are 
released to the shop floor, there is no literature on the shop floor control for such systems.

- There has been little effort in developing and maintaining schedule feasibility, which ensures a smooth workflow and optimum workload conditions in the manufacturing system. Further, the literature reviewed suggested that the objective of a manufacturing control systems was to achieve an optimum system performance based on measures of performance like system utilization, operating cost of the system, tardiness, and flow time instead of ensuring that all jobs entering the manufacturing system be completed on schedule and achieve optimality in system performance in line with that effort.

- The control architectures perform online control but do not pass on the information regarding the delays if any, to the customer, so that they can take necessary remedial actions at their end.

- In case of disturbances occurring in the system, the control systems reviewed do not provide any estimates on the completion/availability of the jobs/resources affected.

- Many systems discussed in the literature assumed a very high level of automation in the job shop manufacturing systems providing very little scope for human intervention. However that is not the case in practice and the human element in the decision making process during control has to be accounted for.

In the following chapters the working of the proposed control architecture, the communication interface between users, the controller and the management (decision making) and the implementation of the system for a dynamic job shop will be presented. 


\section{Chapter Three: METHODOLOGY}

\subsection{Manufacturing Operations System Environment}

The process-planning module of the job shop develops the operation sequence and lists the constraints for the start of each operation for a new job by reviewing plans of similar jobs. The scheduling module develops a forward schedule by translating the process plan into resources (machines, labor, and materials/tools) selection and estimation of its delivery date. Before a schedule is finalized, the system activates the manufacturing simulation module to ensure its feasibility. The manufacturing simulator performs an exhaustive analysis of the developed schedule and provides the scheduling module with a quick tesponse regarding its feasibility or unfeasibility. The schedule is finalized only after a feasible schedule is developed. This ensures that only feasible job schedules are released to the shop floor. The process plan, along with the schedule and the resource allocation data form the input for the control module.

The quality of a factory scheduling process generally has a profound effect on the overall factory performance. Advance generation of the factory production schedules is necessary to coordinate the manufacturing activities in order to meet the organizational objectives (due dates of the orders) and to anticipate the potential performance obstacles. In industrial practice however, the following two factors confound the use of advance (forward) scheduling practices in manufacturing systems:

- Forward schedules result from scheduling systems running with static models that ignore important new operating constraints/objectives of a live shop operation. This is 
due to a lack of a close correspondence to the live status of executed processes and the data resulting from their real time monitoring.

- Forward schedules cannot cope with the numerous environmental and executional uncertainties arising on the shop floor on a daily basis. Unscheduled events like machine break down, worker absence, late deliveries by suppliers etc, all of which work against the efforts to follow the advance (forward) schedule.

\subsection{Shop floor control system}

The performance of the manufacturing facility depends on the control system's ability to rapidly correct the disturbances in the system in order to maintain the jobs on schedule and comply with the organization's objectives. The control system should respond to the changes and disturbances on the shop floor in a timely and cost effective manner. This leads to the conclusion that the manufacturing control system should be reactive in nature in order be able to take corrective actions whenever a disturbance occurs at the execution level of the system. In addition to this, the shop floor control system should also be equipped with the ability to evaluate and predict the impact of the corrective measures taken to counter the disturbance in the system. This implies, when a disturbance occurs at the execution level, the control system should react to the event by taking corrective actions, but before the corrective action is implemented, the control system should perform a thorough evaluation of the impact, which the corrective actions might have on the schedule of the remaining jobs in the system. If the corrective actions have an adverse impact on any other job schedules, then

- other alternate corrective actions are sought, or 
- alternate feasible solutions are selected for the affected jobs.

This process repeats recursively till all the affected jobs are as per the schedule. The control system should therefore be reactive while responding to disturbances in the system and be proactive while implementing corrective measures.

Manufacturing activities requiring control: Reactive control is generally an event driver process carried out on a schedule that has been affected by some disturbance in its execution. The job shop under consideration has sever such events that could cause disturbances in the smooth functioning of the production process. The events can broady be classified into two categories:

- Scheduled events

- Unscheduled events

Scheduled Events: There are three scheduled events, which when delayed, may cause disturbances in the system. These scheduled events are occurrences that are scheduled to take place at a specified time, when the jobs are released for manufacture on the shop floor. The events are:

- Start of an operation: The scheduled time when an operation begins on a job.

- End of an operation: The scheduled time when a job operation ends.

- Arrival of material/tools: The scheduled time when bought out materials/tools for a particular order arrives into the system.

Unscheduled Events; There are four unscheduled events, which may cause disturbances in the system performance. The unscheduled events are random occurences, which cannot be planned for in advance. The events are: 
- Release of a manufacturing order: In the manufacturing system, since all the job schedules are feasible and the job is scheduled for manufacture only after taking into account the shop load and the avalability of the material and other preceding constraints, the job enters the control system once the manufacturing order has been released, but the production activities begin when the first operation is scheduled to start.

- Machine break down: This event occurs whenever a machine becomes unavalable due to some breakdown or unscheduled maintenance.

- Worker absence: This event occurs when a planned resource like workers report late to work or are reported as absent for the scheduled operation time.

- Correction of the information of a prior event: Erroneous information regarding any of the previous events described above could be relayed to the controller from the shop floor. This event occurs largely due to human error and preventive actions should be taken at the design stage to avoid such situations. The control system should be capable of collecting the correct information and take appropriate measures to check for any adverse impact of the incorrect information on the execution of the schedule.

\subsection{Control System Architecture}

In the context of shop floor controt, an architecture provides the blueprint for the design and construction of an SFCS (shop floor control system). It should completely and unambiguously describe the structure of the control system as well as the relationships between the system inputs and the system outputs. Control architectures are the 
fundamental building blocks on which control system design progresses and as such directly influence the flow of control, monitoring information and the interaction of manufacturing components. The performance of the control architecture on these dimensions, given the complex and dynamic environment of advanced manufacturing, can ultimately determine the viability of the manufacturing system

The proposed control system for the manufacturing system will have a hierarchical structure, with the controller making all the decisions at the workstation level and the manager at the shop level, on the basis of the information received from the shop floor and the shop load conditions. Since all the jobs that are released for manufacture to the shop floor have a defined process plan and a feasible schedule, the operations of all the jobs have a scheduled start and finish time. The resource allocation (machines, workers and materials/tools) is listed in the schedule when the manufacturing order is released to the shop floor. Further the controller also knows, at any given point, the total number of orders that have been released to the shop floor. It is the controller's primary responsibility to check whether the operations on the shop floor are following the schedules. Based on the above information, the following terms have been defined; these terms will be used in the control system being developed for the job shop environment.

Control list: This is a list of all the orders released for manufacture, the jobs are ether waiting for the processing to begin or are being processed on the shop floor.

Scheduled Event List: The scheduled event list is a chronological list of all the scheduled events (operation start time, operation end time and material/tools arrival), of all the jobs listed in the control list. The list includes all the constraints and precedents related with 
each event as listed in the process plan of that particular job, the contact person on the shop floor and the specific deparment where the job will be processed.

Data Collection: The information exchange between the shop floor and the controller is dynamic in nature and will be in real time through web pages on the Internet. Every time an event occurs in the system, the concerned user on the shop floor notifies the controller and every time a corrective action is to be taken, the controller relays the information back to the shop floor through web based communication. However, the user may sometimes relay information about a particular event in advance. This offers the controller the opportunity to be proactive if the information can be used effectively. Potentially, the information on the status of any of the seven events that take place on the shop floor can be relayed to the controller ahead of schedule, on schedule or it can be late. The following table depicts the possible states of the information exchange between the shop floor and the controller.

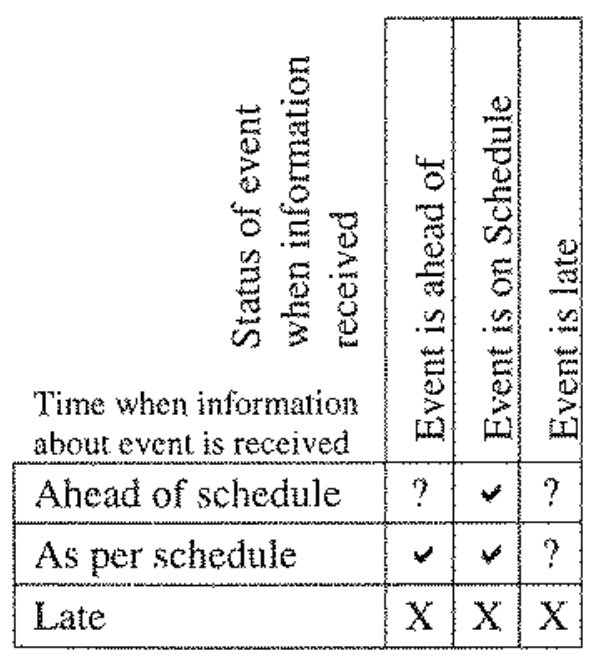

Table 1. Information received - Event status matrix. 
The above matrix shows the various states of the events scheduled and unscheduled) and the possible times when the information can be made available to the controller. The matrix shows that information regarding an event status from the shop floor cannot be received late. The Scheduled Event List contains all the events that are scheduled to occur on the shop floor. When information about a particular scheduled event is not received from the shop, the control system will initiate an inquiry and ascertain the status of the event from the concerned user. All the other states in the matrix pertain to information received from the user. The controller takes action on the information received only if the event causes a (disturbance) delay in the order schedule. This feature of the control system keeps a constant check on the order status. From the above matrix, it can be seen that the controller needs to evaluate the following reports sent by the user:

- information on an event due for completion ahead of schedule

- information on an event that will be late

- information on an event that is late

The flow of information in the control system for the target manufacturing system environment is as shown in a flow chart in figure la. 


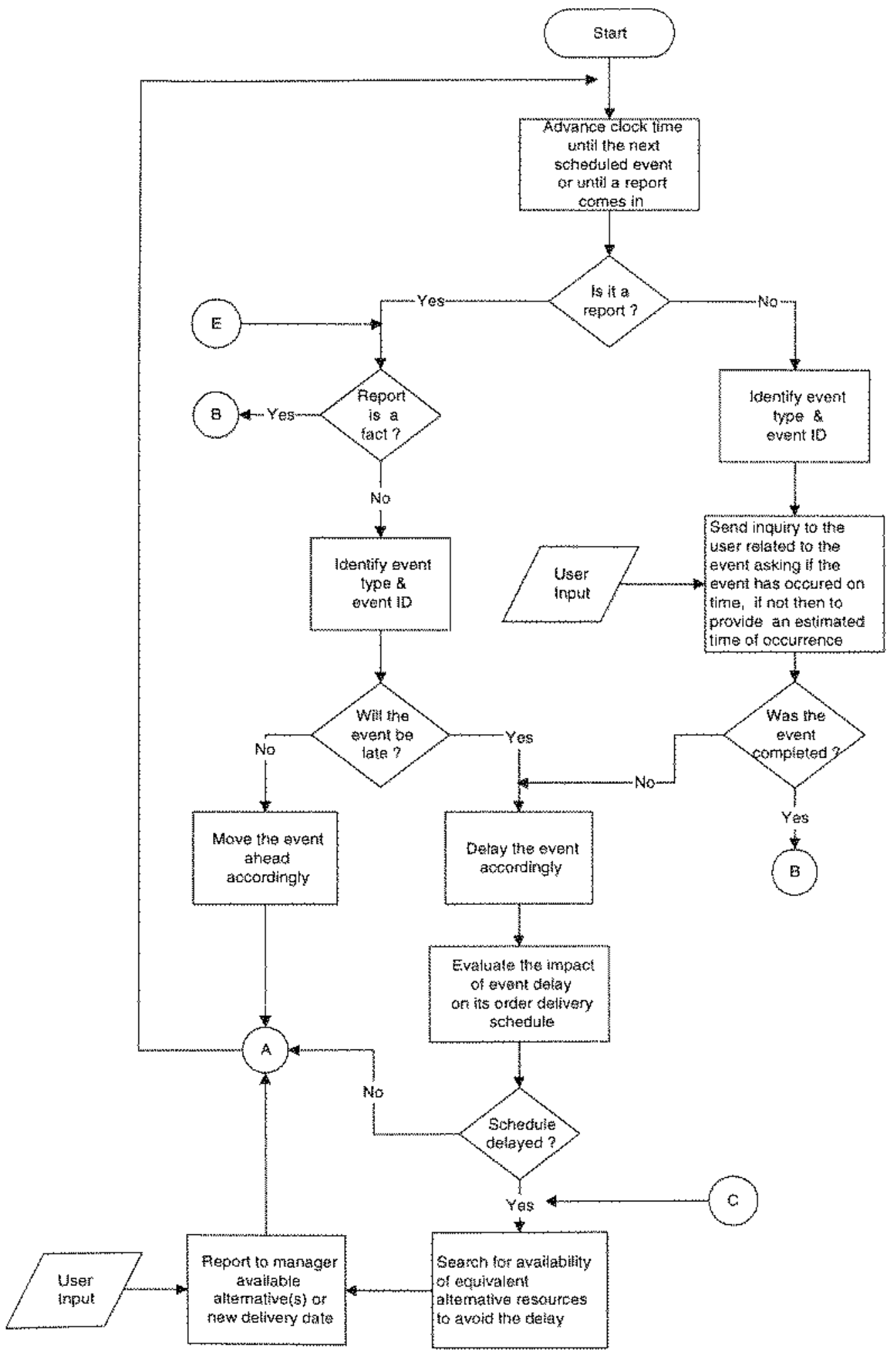

Figure 1a. Shop floor control system 
Control mechanism: The control system is a real time monitoring system. The system is reactive in nature and checks to see if the events in the scheduled list are on time. If there is any delay, the manufacturing simulation module is triggered and feasible alternate resources are suggested, if no resources are available then a search for alternate corrective actions is triggered. The information flow in the model occurs in the form of information requests from the controller to the shop floor and reports on the execution of scheduled events, from the user on the shop floor to the controller. Thus, the flow of information is vertical. When the flow is downwards, it corresponds to a request made by a hierarchically higher entity (the shop controller) for information to be provided by a lower layer entity (the user). When the flow of information is upwards, it is a report of the current status (completion of a scheduled event or occurrence of an unscheduled event) on the shop floor. Thus, there are three forms of communication between the user on the shop floor and the controller.

- A request for information from the controller to a user when the report on a scheduled event is not recejved as per schedule

- The user sends a report of a fact (occurrence of an event) from the shop floor.

- The user sends a report of an estimate of an event occurrence.

Request for information: When the report for a scheduled event does not arrive as per the schedule, the system initiates a check by sending an inquiry requesting information from the user related to the scheduled event. If the event is on schedule, the user responds by sending a report stating the same to the controller and the event is marked off the scheduled event list, the constraints related to the event is updated and the time is recorded. In case the event is not completed, the user provides the controller with an 
estimate for the completion of the event. The controller then checks to see if the delay in the event causes a delay in its order delivery schedule. If there is a delay, then the manufacturing simulation module is triggered and a feasible alternative is sought. The controller collects all the data associated with the current shop floor activities and emulates the activities on alternate feasible schedules. This includes searching for equivalent resources (machines or workers) to check if a feasible alternate solution exists such that the job will be completed within the scheduled time frame. If the search fails to provide a feasible alternate solution, then a new estimated delivery date is proposed to the manager for approval. (Refer figure la)

Report of a Fact from the User: Every time a scheduled event is completed or an unscheduled event occurs on the shop floor, the user related to the event sends a report to the controller. This report contains factual data on the events taking place on the shop floor. The report could be of any of the following types:

- If the report is regarding the completion of a scheduled event, the controller marks the event off the scheduled event list, updates the constraints related to the event and records the time.

- If the report states the release of a manufacturing order, then the order is added to the control list, all the events and constraints related to the events are recorded in the scheduled event list

- If the report pertains to an unscheduled event (resource unavailable), then the systen determines the event type (machine break down/worker unavaitable) updates the relevant resource record and evaluates the impact of the downtime on the job 
schedule. If there is a delay because of the event, then the manufacturing simulation is triggered and alternate resources are sought to avoid the delay.

The flow chart in figure $l b$ represents the control system when the user sends a fact report. 


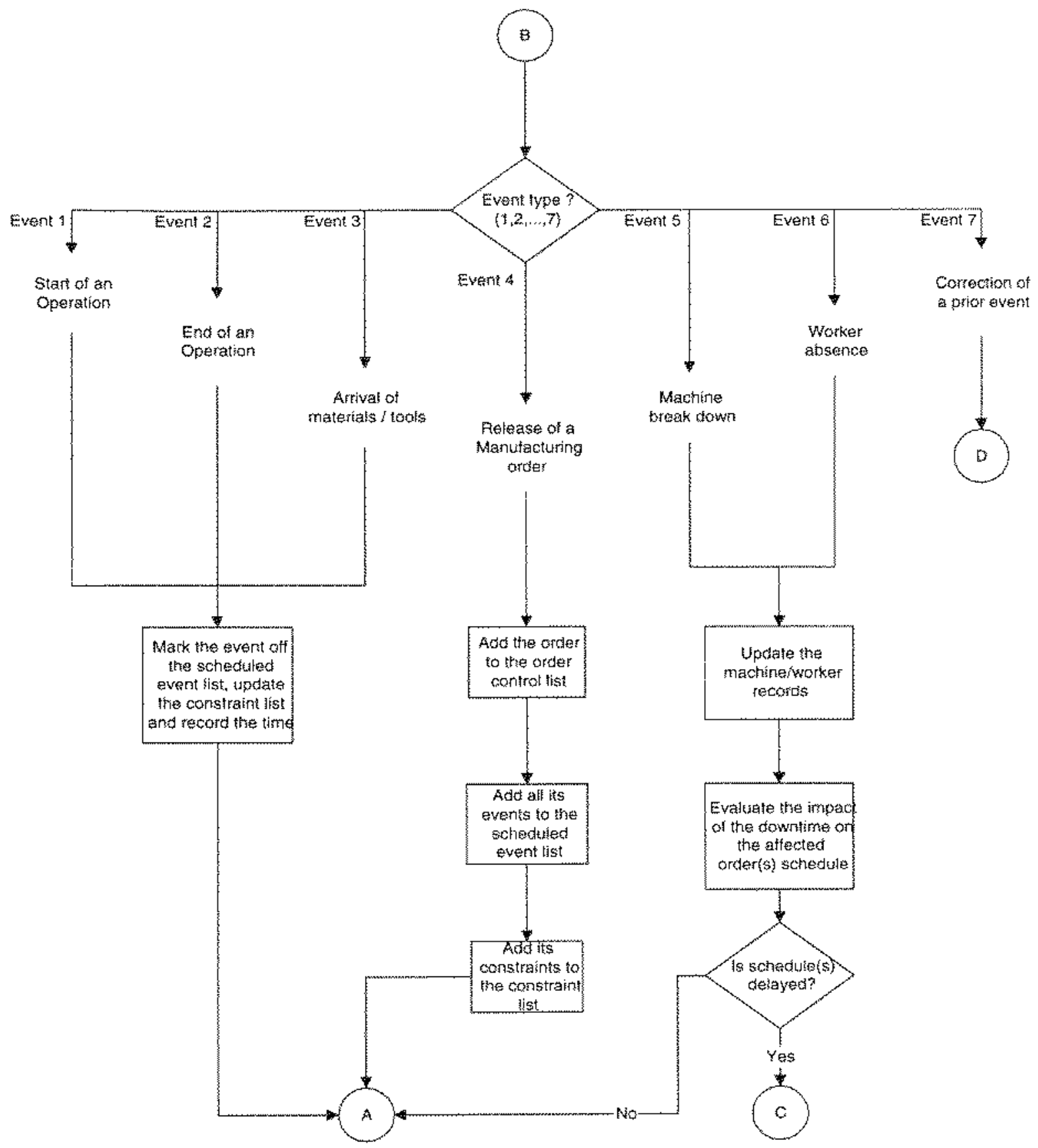

Figure 1b: Report of fact from User

Another kind of report the controller may receive from the user refers to the correction of an event reported earlier. Such a report could be about any of the other six events (operation, startfinish, material/tools arrival, machine breakdown/worker unavailable, 
and release of manufacturing order) described earlier. When such a repont arrives the control system can take any of the following actions:

- If the report corrects the information of a scheduled event reported earlier, then the incorrect information entered in the system is undone (the incorrect information is deleted and the correct information is entered).

- If the report corrects the information regarding the unavailability of a resource (machine break down/worker absence), then the resource records are updated and the resource is reactivated in the control system.

- If the report corrects the information on the release of a manufacturing order then the controller checks to see if the job processing has begun. If it has begun, then the controller brings this to the manager's notice and waits for further instructions. If the processing has not begun then the job is taken off from the control list, the scheduled event list and the constraint list are corrected accordingly. The flowchart in figure Ic. depicts the control module proposed for the target manufacturing system environment. 


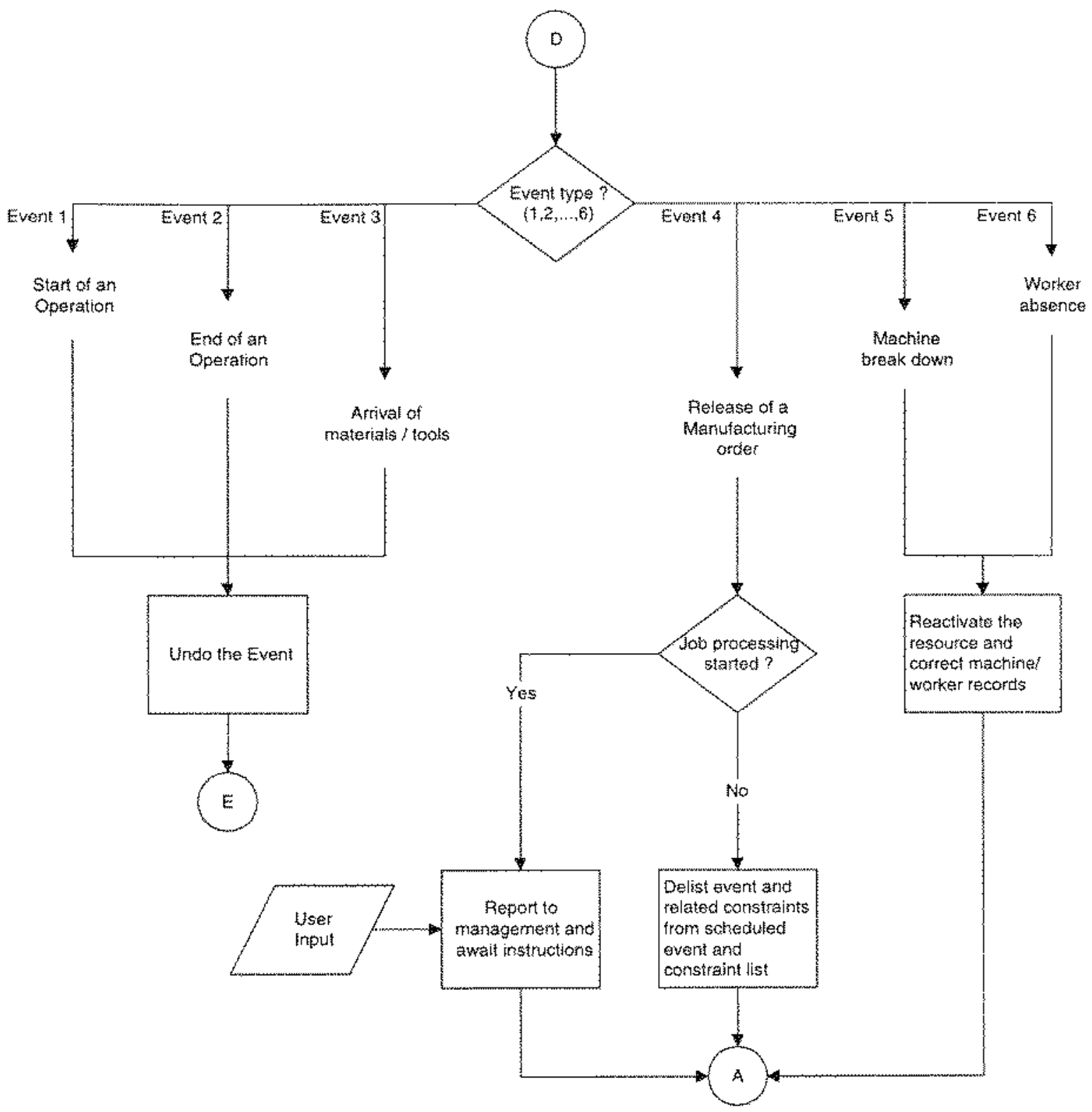

Figure $1 \mathrm{c}$. Correction of a prior event

Report of an estimated time of an event occurrence: When the user knows, that for some reasons a particular event will either be ahead of schedule or will get delayed, he can inform the controller of that possibility by sending a report with an estimated time of the event occurrence. If the event is going to be ahead of schedule, the controller only has to update the scheduled event list by moving the event ahead accordingly. If the event is 
going to be delayed, then the controller delays the completion of the event in the scheduled event list accordingly and determines if the delay will have an adverse impact on the order delivery schedule. If there is a delay then corrective action is taken as described earlier. 


\section{Chapter Four: IMPLEMENTATION}

\subsection{Manufacturing Operations Environment}

The manufacturing system under consideration is a dynamic job shop with fixed order due dates, and manufactures a large variety of parts for assembly. Orders are continuously arriving into the system and the various jobs to be produced are broken down from the Bill of Material (BOM) prepared for the order received from the customer, to make the single level and/or assembly level products. The process plan follows a forward scheduling procedure, thus creating a realistic and feasible production schedule giving the planned start and finish times of each operation at a particular work center and worker, thereby allocating resources to each job before it enters the production system. Material and tool requirements specified in the process plan are linked to the production schedule, and are either out sourced or manufactured in house in such a manner that the materials/tools required for each operation are identified and delivered in the required quantity at the specified operation time.

The manufacturing system operation architecture has a GUI web page design for user interface, application modules and a database system. The system is Internet-based and runs of the Windows NT platform. The user interface includes pages of tables and forms for entry and update of job orders, resources, operations/plans and knowledge to facilitate system operations and maintenance. The database stores both data and knowledge. The data includes job orders, schedules, and resources. The resources include human resources, machines, equipment, and raw materials. The knowledge base contains 
standard operation plans, product/operation knowledge, and operation/resource knowledge. The knowledge is organized into forms, charts, and/or tables.

The application modules include order tracking, order processing, process/operation planning, (production) scheduling, manufacturing simulation (emulation), inventory control (MRP), shop floor control (WIP and resource status), and meeting/staff scheduling.

\subsection{Manufacturing Operations System Environment}

The process-planning module of the job shop develops the operation sequence and lists the constraints for the start of each operation for a new job by reviewing plans of similar jobs. The scheduling module develops a forward schedule by translating the process plan into resources (machines, labor, and materials/tools) selection and estimation of its delivery date. Before a schedule is finalized, the system activates the manufacturing simulation module to ensure its feasibility. The manufacturing simulator performs an exhaustive analysis of the developed schedule and provides the scheduling module with a quick response regarding its feasibility or unfeasibility. The schedule is finalized only after a feasible schedule is developed. This ensures that only feasible job schedules are released to the shop floor. The process plan, along with the schedule and the resource allocation data form the input for the control module. The manufacturing operation system architecture is as shown in figure 2 


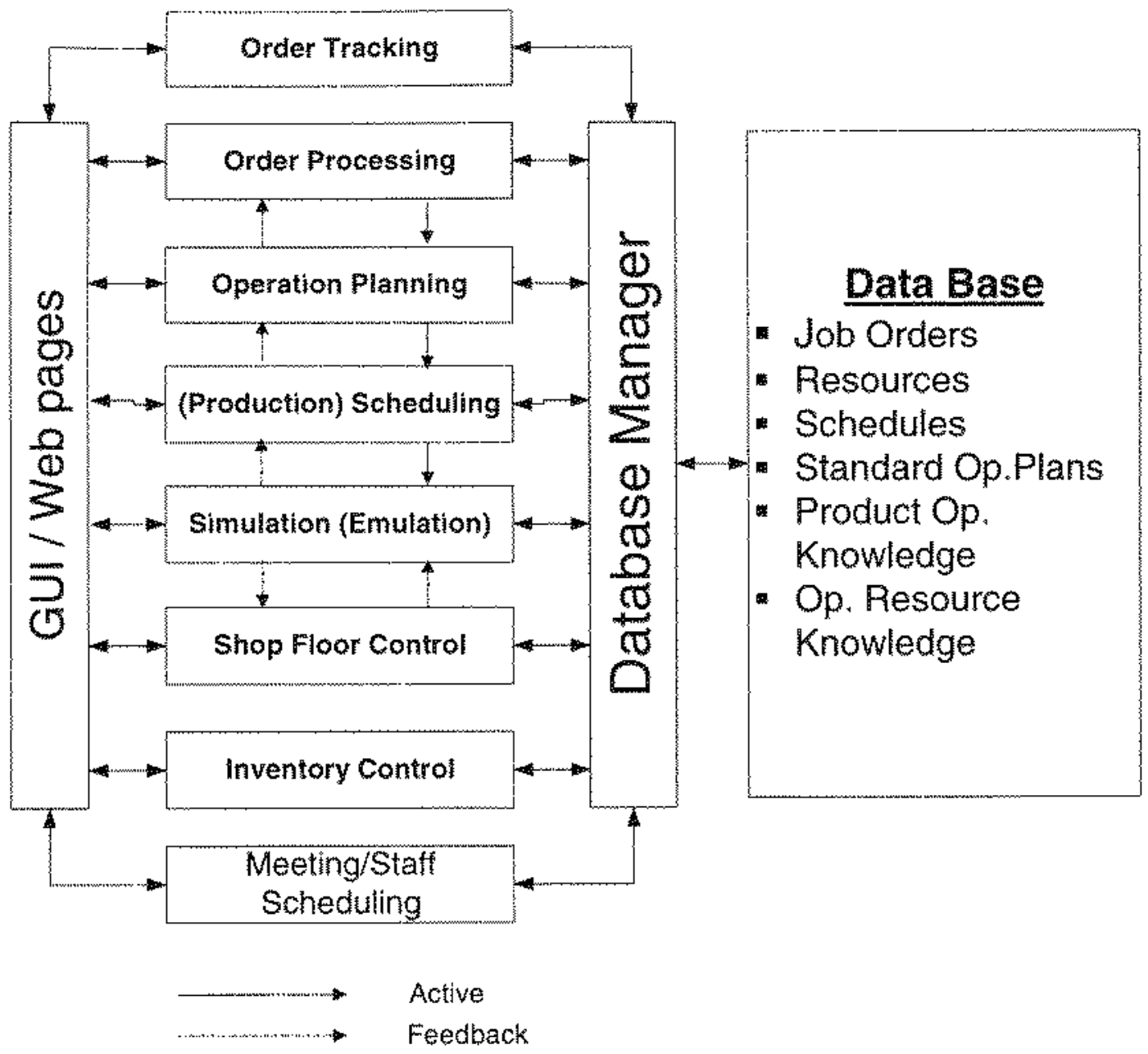

Figure 2. Architecture of the manufacturing operation system.

\subsection{Implementation Environment}

The entire manufacturing system uses a common database, which is built using the Microsoft Access software. The database houses all the data tables, which the system accesses from the net through a standard ODBC driver. The information in the various tables include data fields like customer order details, the bill of materials for the orders processed in the manufacturing system, the capability and availability of the resources in the manufacturing system, the different operations performed by each of the resources in the system, the process plan template and header information, the scheduling template 
and header information, the various types of events that the system has to record and analyze, and the various work groups and work centers into which the resources in the manufacturing system are organized.

The forms used to present the data to the users of the system are developed using VB, VB script, Java, Java script and Active Server pages (ASP). The shop floor control system is shown in the block diagram in figure 3.

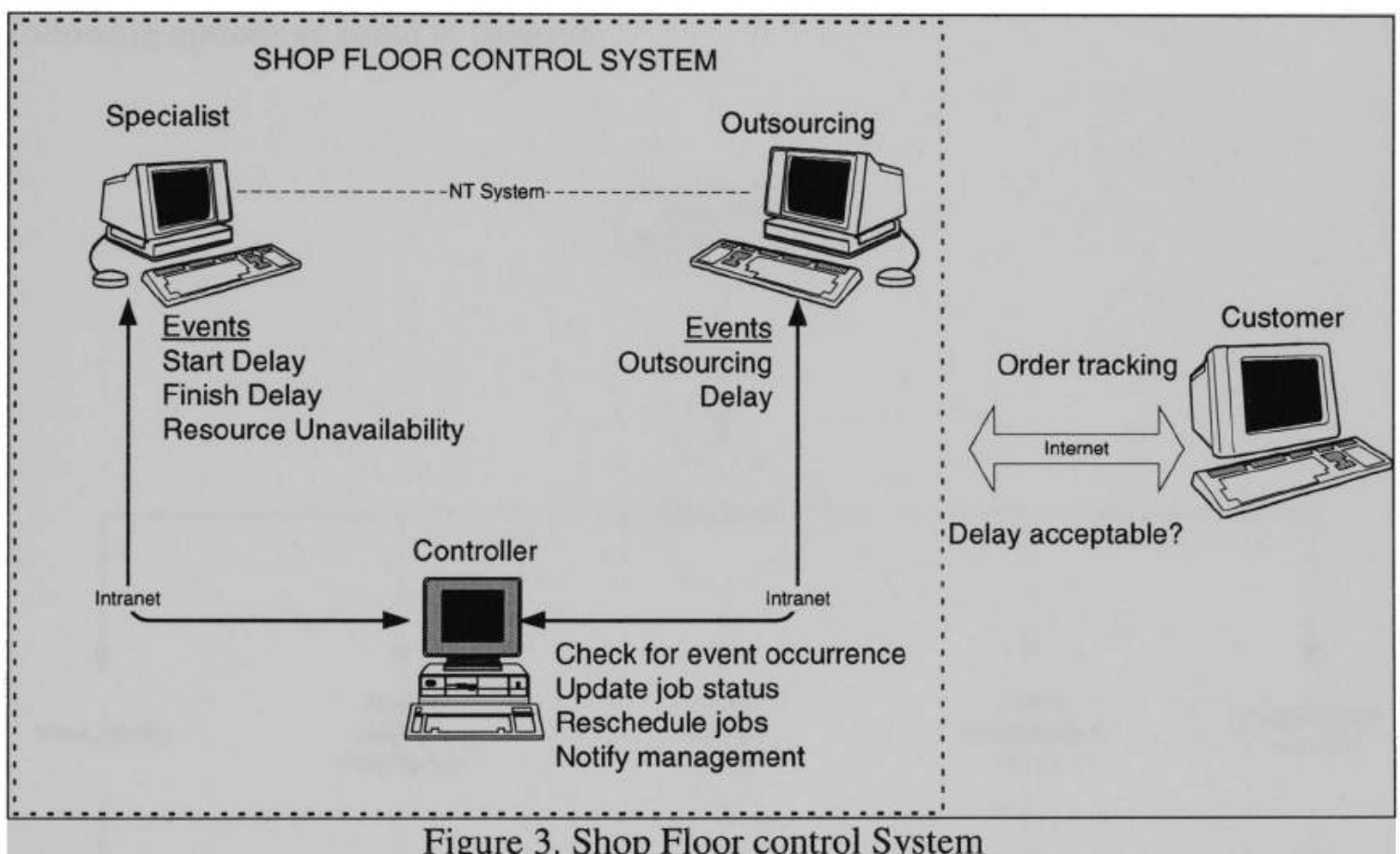

\subsection{Shop floor control system architecture}

The shop floor control system has three types of users interacting with each other to perform the shop floor control of the operations in the manufacturing floor:

- The Shop floor controller,

- The specialists on the shop floor,

- The outsourcing specialist responsible for the jobs that are outsourced. 
The system has three different forms (web pages), which can be accessed by each of these users.

The Specialist Web page: Each user on the shop floor is referred to as specialist in his/her designated group/field. Each specialist has a unique logon ID and password, which permits him/her to $\log$ into the system. The system recognizes the user's log on ID and takes him/her to the specialist page, where the user can choose from among the following options as listed in figure 4:

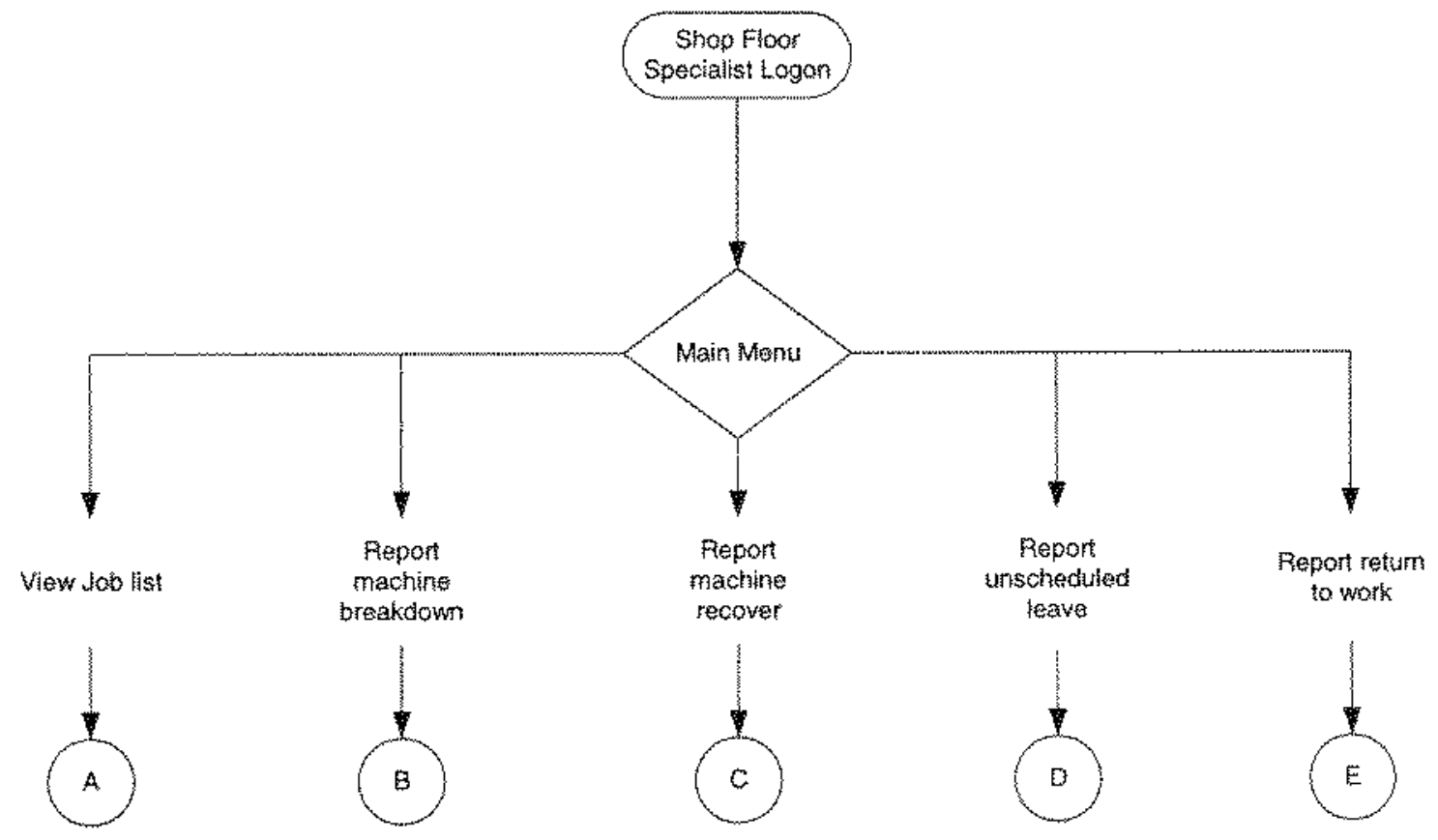

Figure 4. Specialist menu options. 


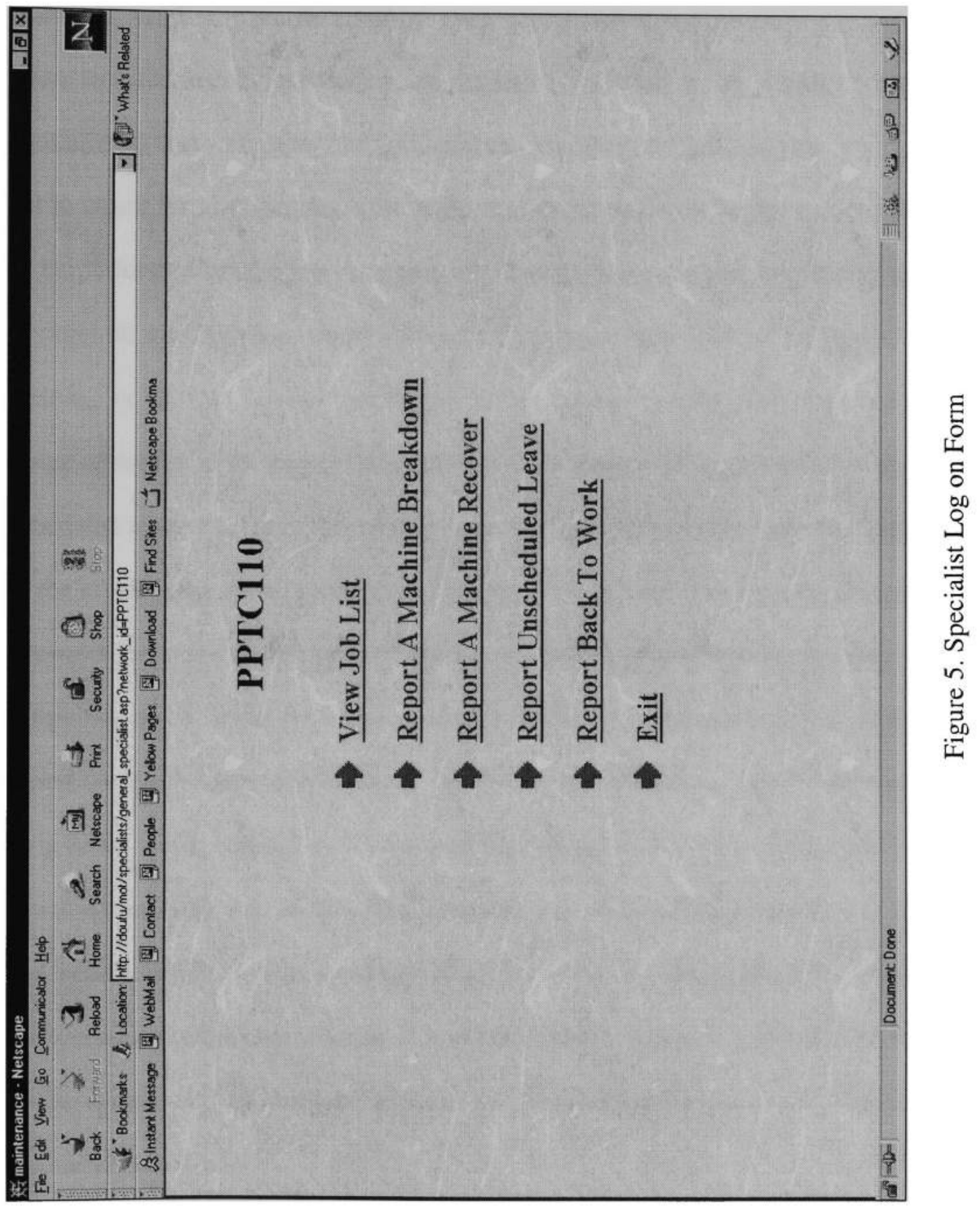


View Job List: The system recognizes the user's $\mathrm{WD}$ and loads the relevant jobs assigned to the particular specialist. The relevant job details like the job $\mathrm{D}$, the product name, the operation number, type, description, work center, scheduled operation time, number of hours required to complete the job and the status of the job are the details presented to the specialist on this web page. The specialist can also view the process plan of any job in the list to check for any specific instructions that might be listed for the particular operation to be performed on the job. The specialist has to select the job assigned to him/her by clicking on a radio button next to the specific job and then click on the type of operation (starting or finishing) being performed at that scheduled time. The system updates the status of the job in the appropriate field in the database and future event list of the events scheduled to take place in the system is updated accordingly. This informs the controller of the actual status of the particular operation to be performed on the job. (Figure 6) Report A Machine Breakdown: Whenever there is a breakdown on the shop floor, the specialist has to report the event to the controller. The specialist clicks on this link to report the breakdown. The specialist can select the affected machine/work center from a drop down menu, which lists all the work centers in the shop floor, and report the time at which the machine has become unavailable as well, the estimated time when the machine will become available again and key in the reason for the down time in the machine. This sends a report to the controller and the event is added to the control events to be resolved in the system and all the jobs affected by the work center's unavailability need to be studied (Figure 6). 


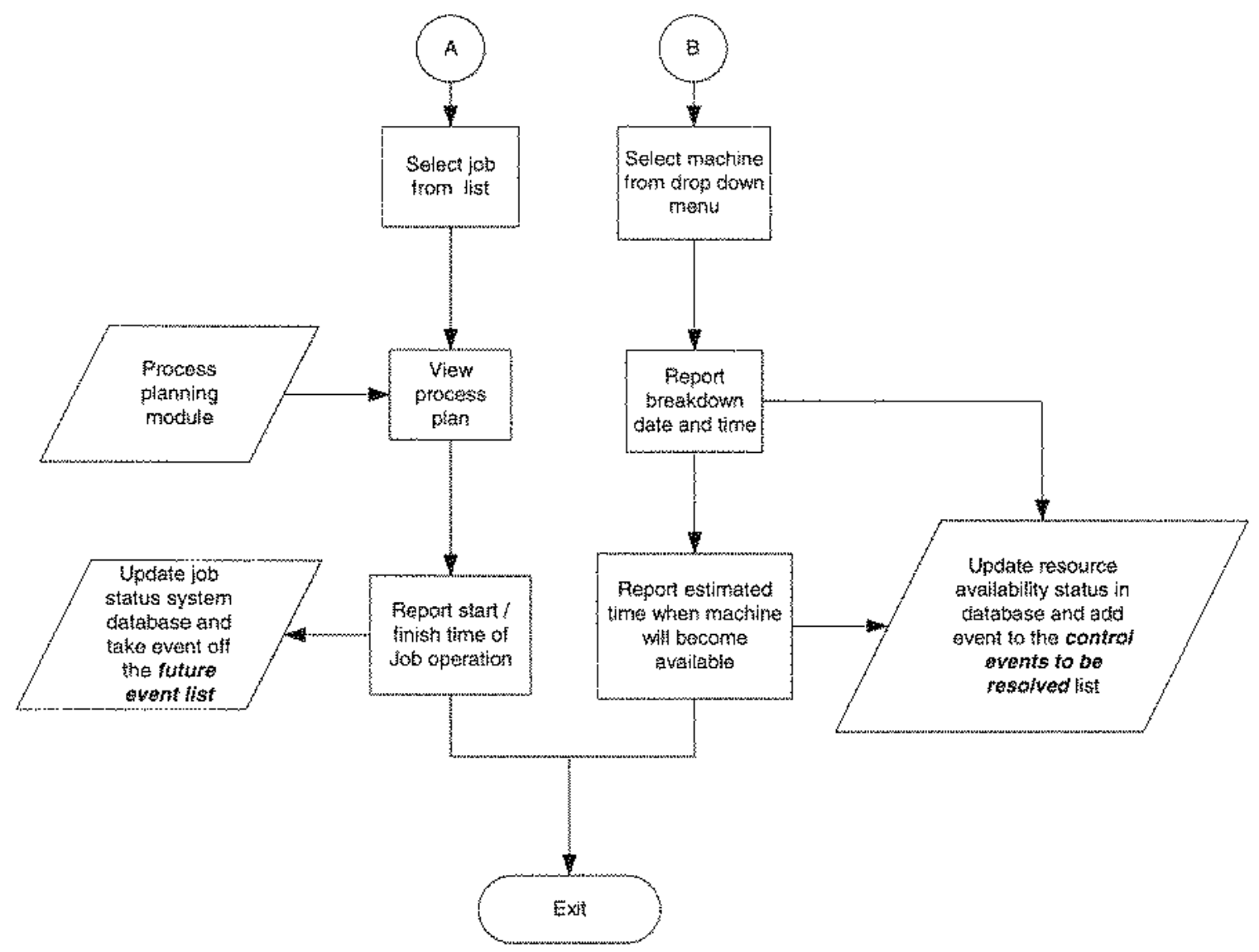

Figure 6. View job list machine broken down options

Report A Machine Recovery: Once a machine has undergone some repair or maintenance and is back in operation, the specialist has to report the event to the controller so that the particular resource can be taken into account while performing the various control decisions. The specialist has to report the time at which the affected machine actually becomes available. (Figure 7)

Report Unscheduled Leave: This is to capture the information when a specialist becomes unavalable due to unscheduled leave. The specialist's absence can be reported by either the specialist himself (in case he/she knows if they will be absent from work in advance) or by the supervisor in case the specialist is unable to report to work on a particular day. 
The user logs (specialist or the supervisor) into the system and reports the estimated duration of time and the reason during which the specialist will be absent from work. The absence is recorded in the control events to be resolved table of the system and all the jobs affected by the specialist's absence need to be studied (Figure 7).

Report Back To Work: The user notifies the controller when he/she has resumed regular duties. This is a confirmation of the resource becoming avalable in the system at the scheduled time (Figure 8).

Exit: The user logs off from the system

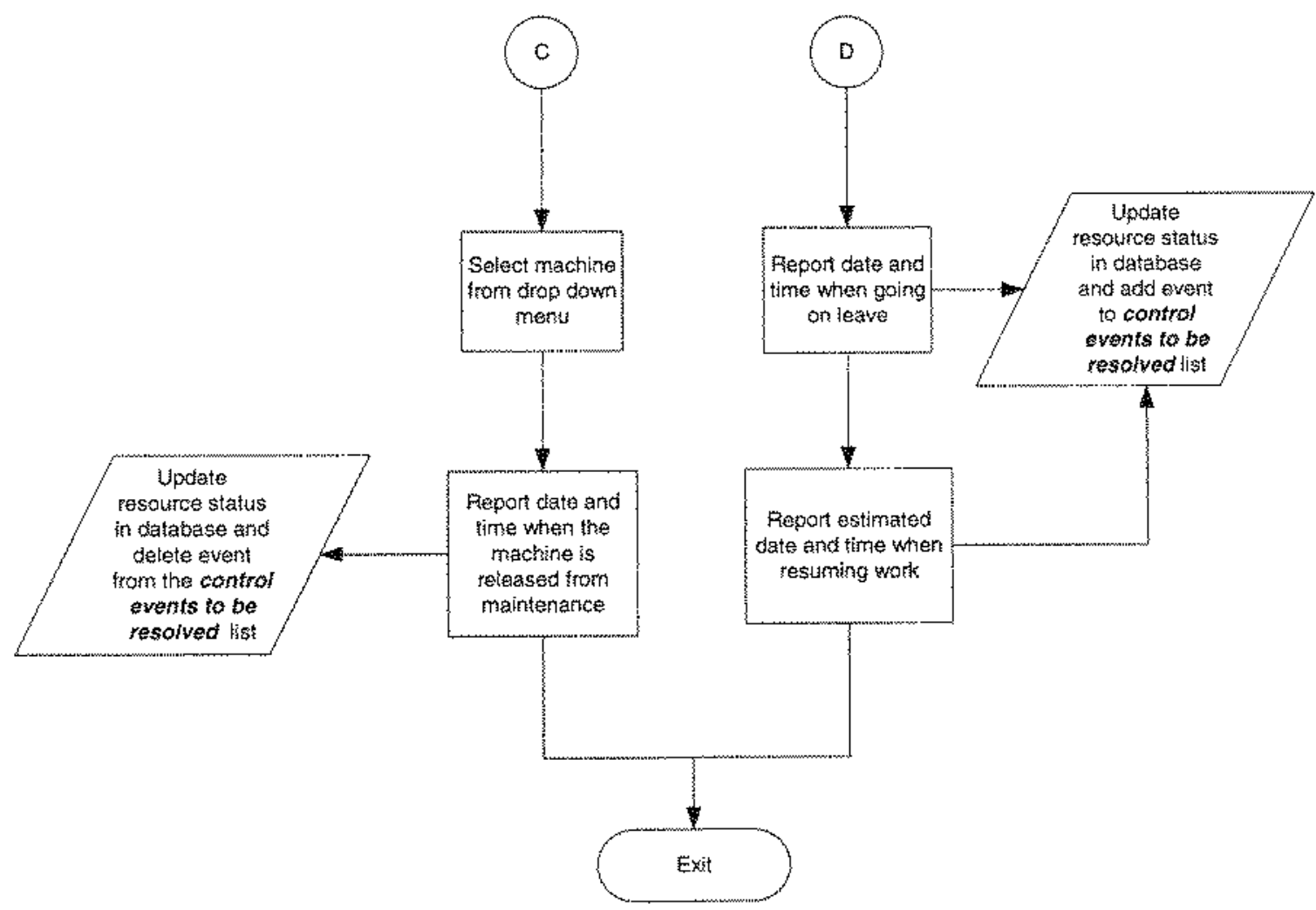

Figure 7. Machine recovery/Worker absence options 


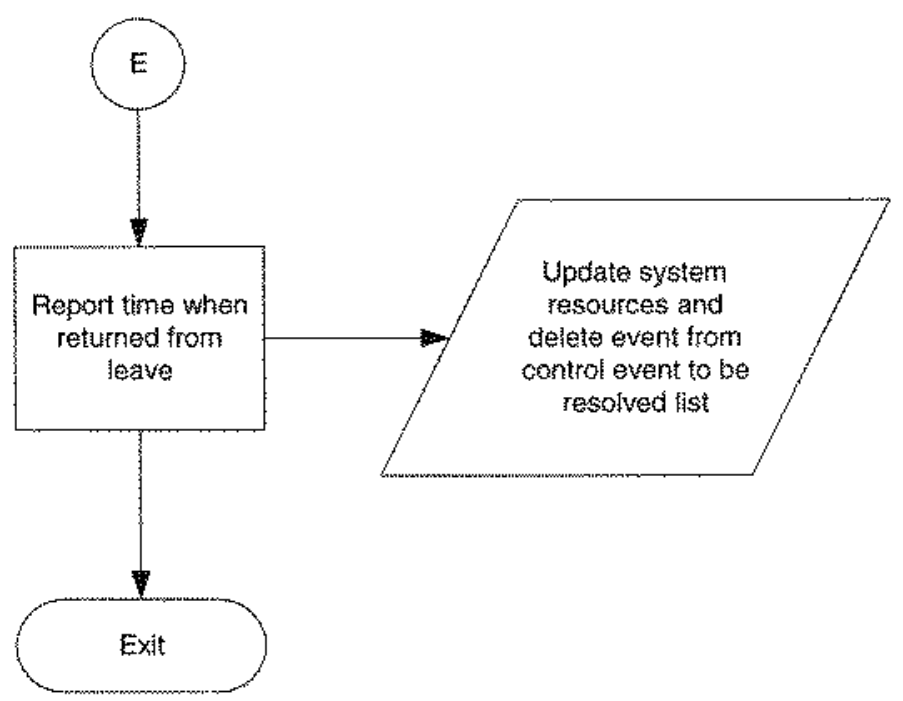

Figure 8 . Wotker return option. 


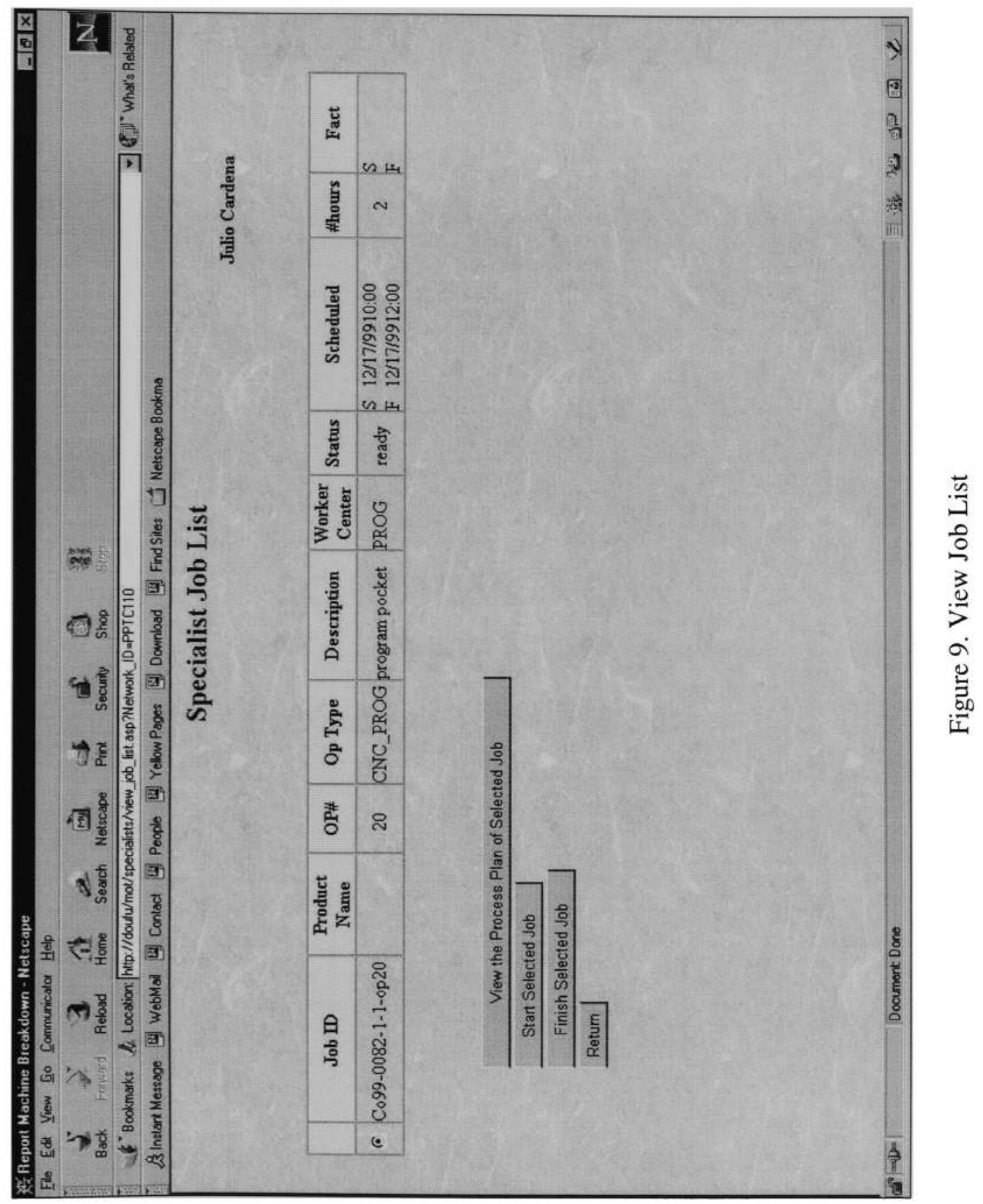




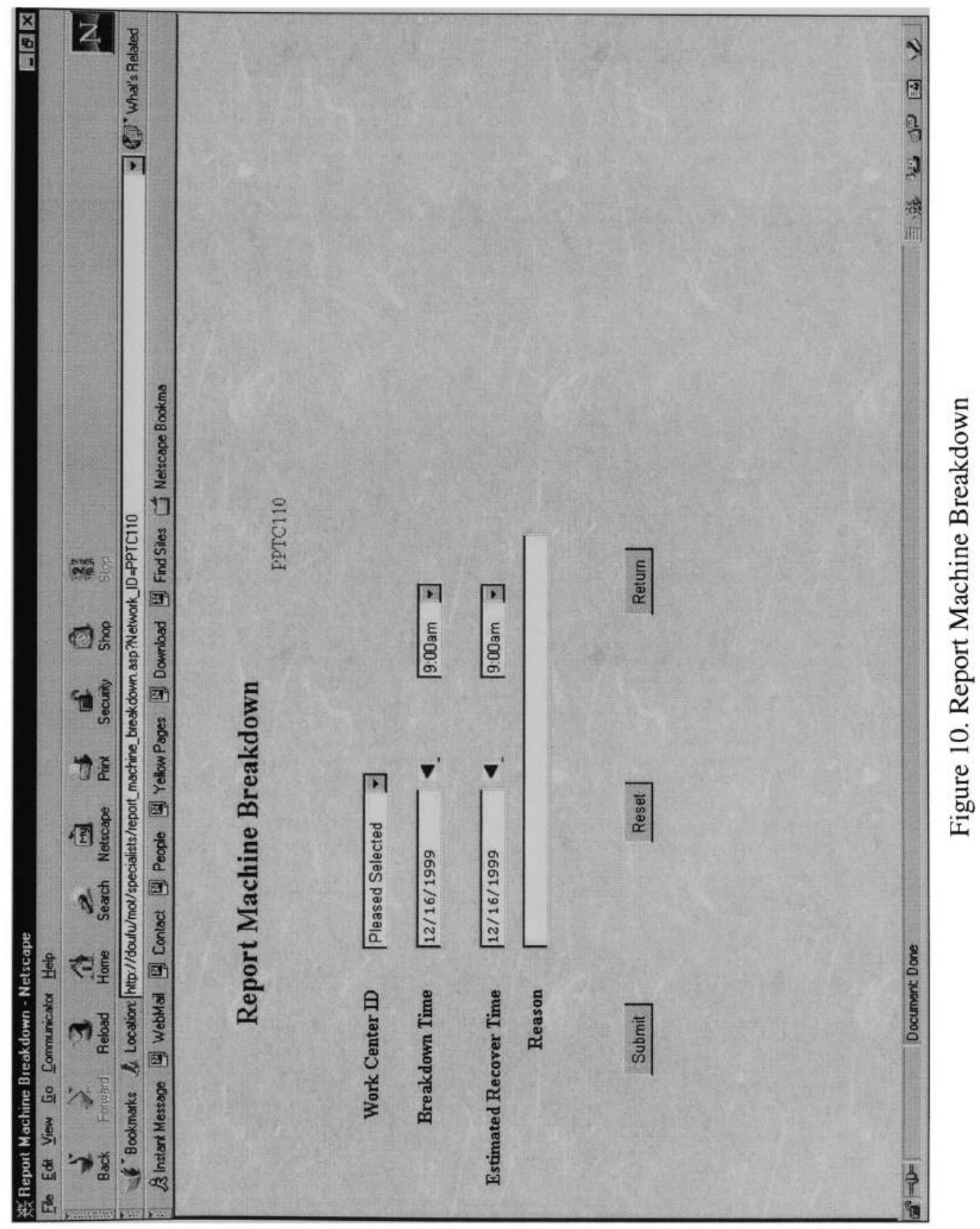




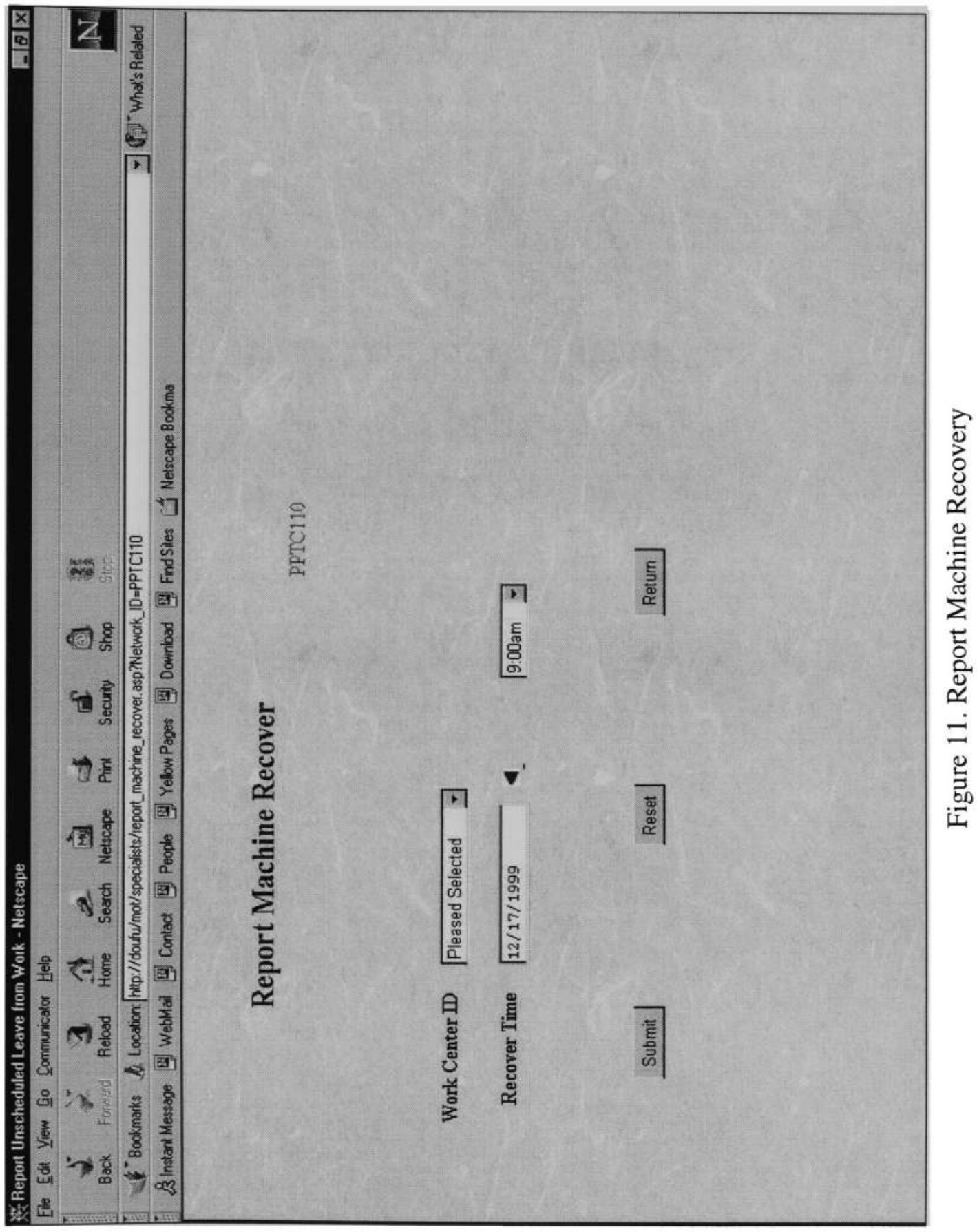




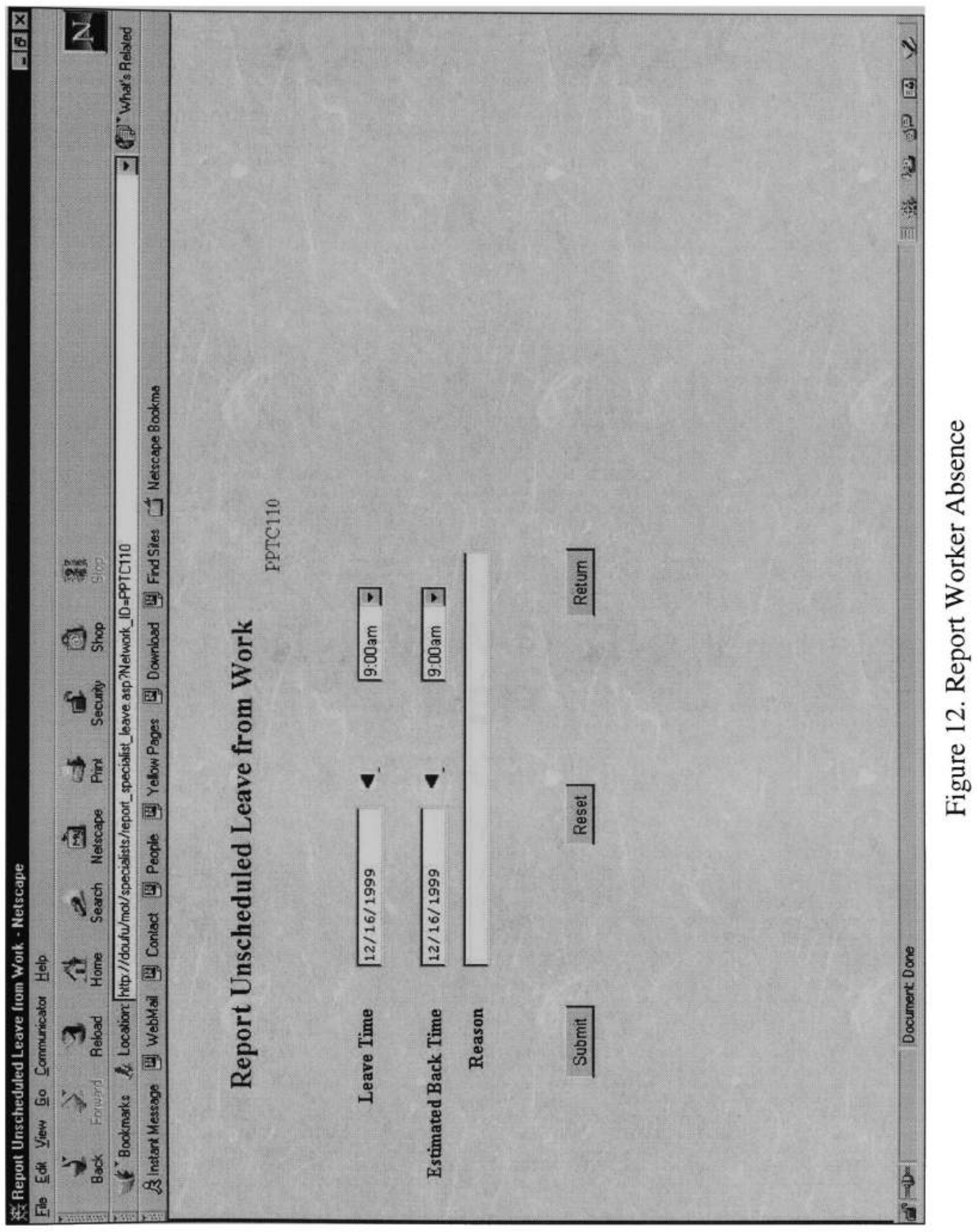




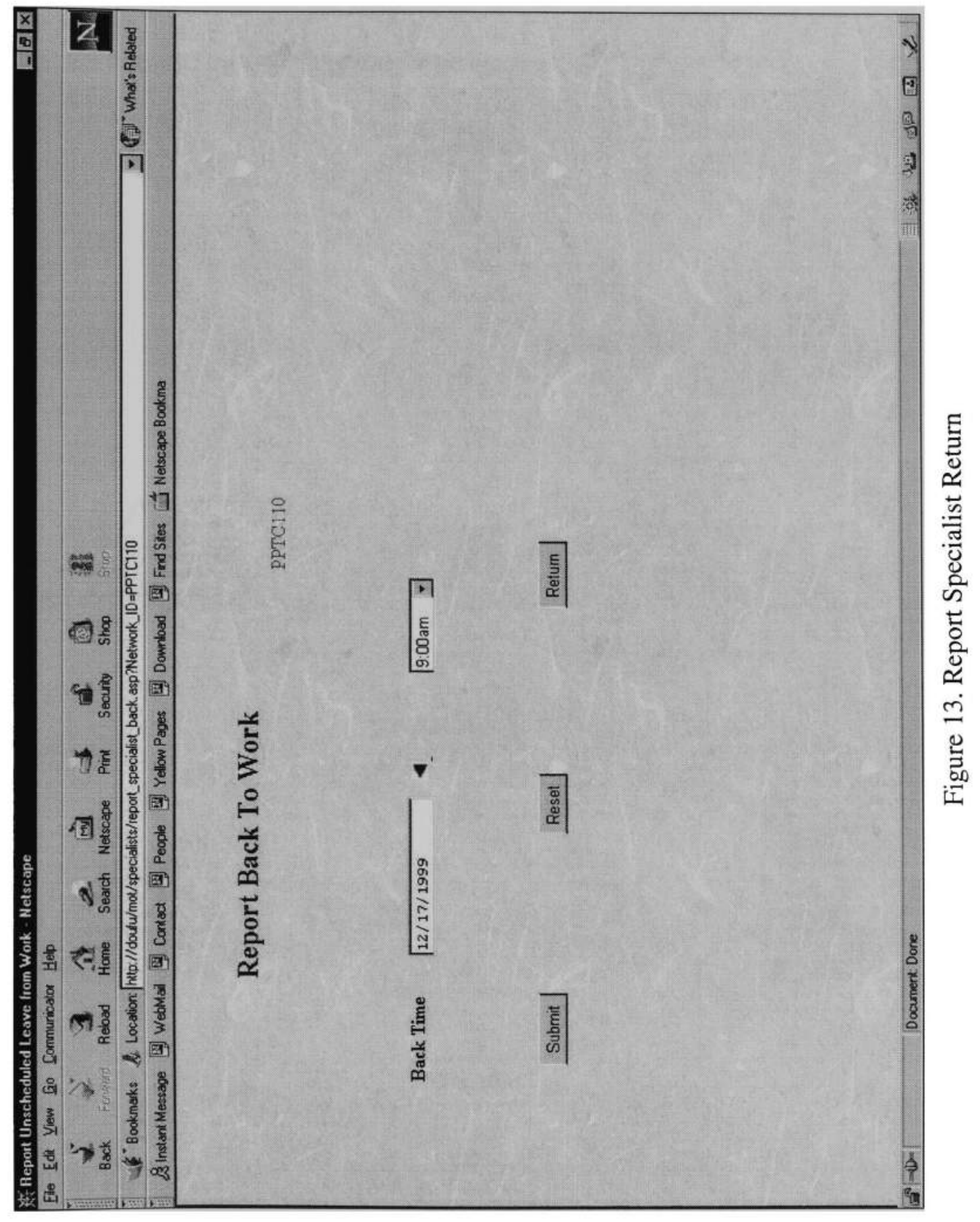


Outsourcing web page: The outsourcing specialist is not directly under the purview of the shop floor control system, but decisions taken by this specialist have a direct impact on the control issues on the shop floor. All the outsourcing jobs are constraints to jobs that are released into the manufacturing system.

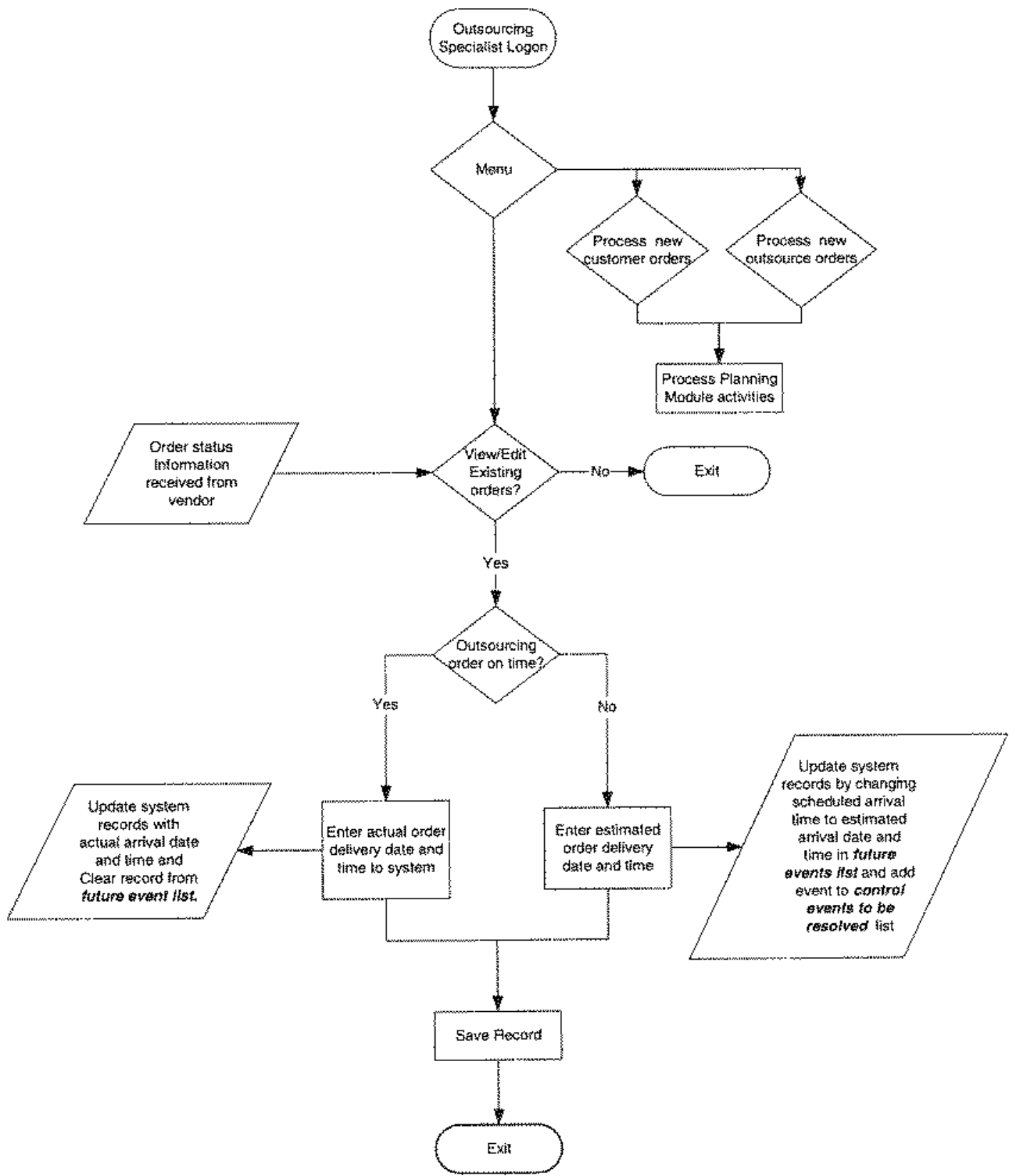

Figure 14. Outsourcing system algorithm 
The outsourcing specialist has the following options available to him as shown in figure 15: 


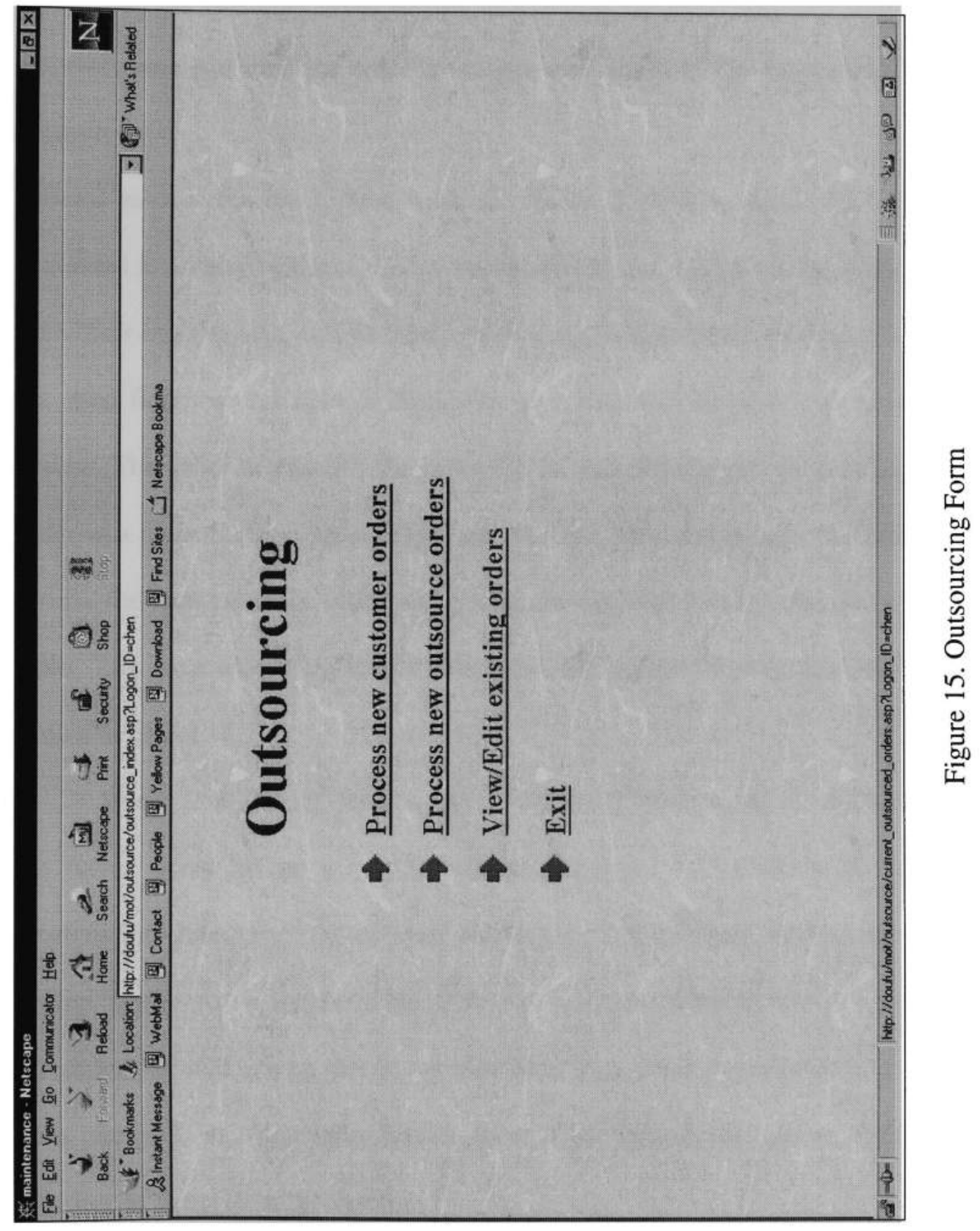


Process new Custoners orders: This link loads a web page, which provides a complete list of all the customer orders that are being considered for outsourcing. All the relevant details like the customer order ID, the description, quantity, date and time the order was received, date and time the order is needed, and details of the department requesting the outsource.

Process new outsource orders: This link loads the list of outsourced orders that are generated internally by the different departments in the manufacturing system.

View/Edit existing orders: The third option is where the system generates issues related to the shop floor control system. The web page lists the currently outsourced jobs in the system. The order details like the order $\mathrm{D}$, the job description, the quantity, the date the order was placed, the group needing the item, the specialist placing the order, the vendor details, the date when the order was placed, the estimated arrival date are provided in this table. The page also provides provision for the actual delivery date to be filled in as shown in figure 16.

Every time the expected delivery date is delayed (either when the system checks the future event list or when the outsourcing specialist checks with the vendor and receives information on the delayed delivery date) the system generates an event to the control events to be resolved list. This notifies the controller that the constraint for a scheduled job will not be met at the scheduled time since the estimated delivery date has been changed. The controller has to look at the impact this delay might have on the schedule of the jobs in the system 


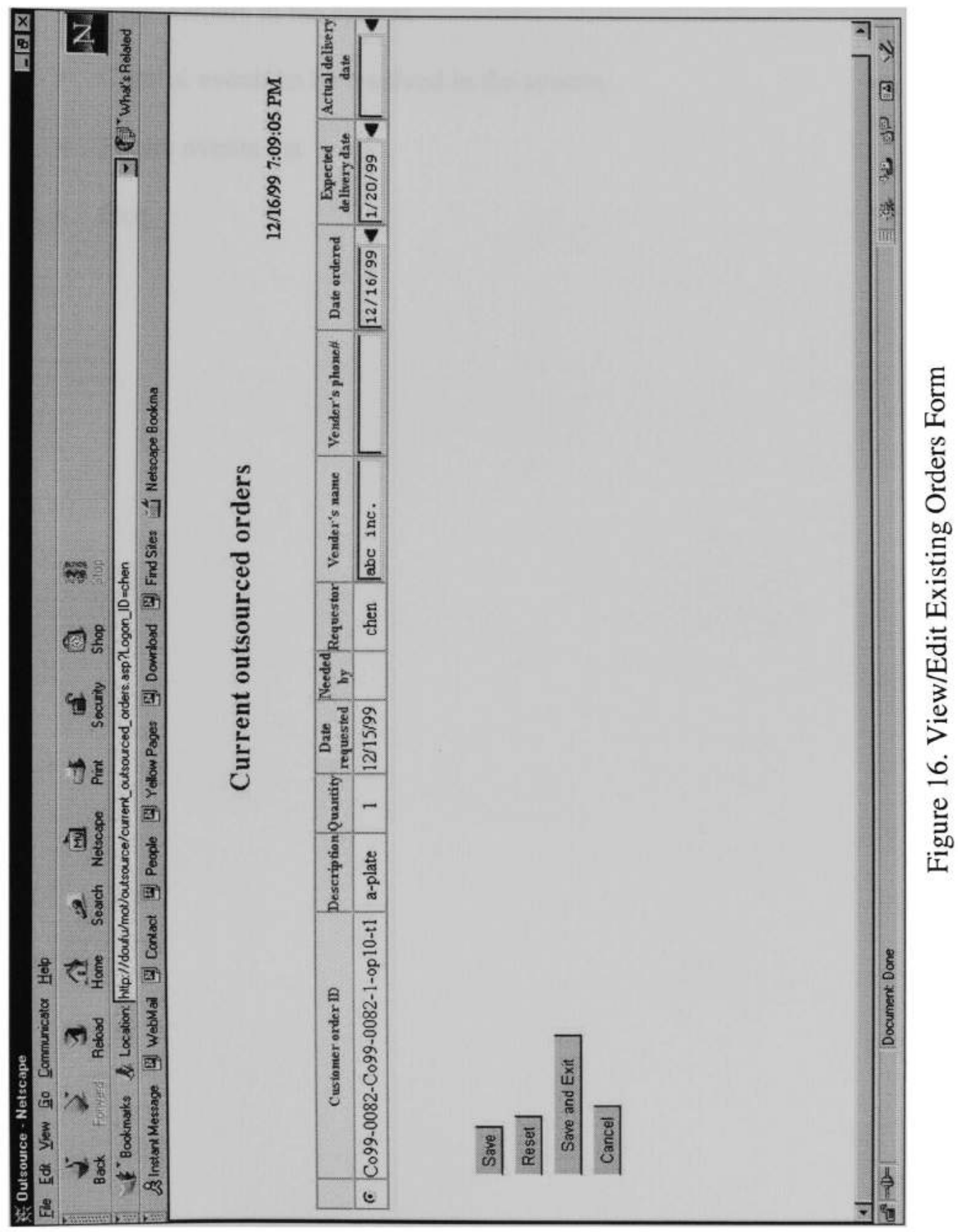


Shop Floor Control web page: The shop floor controller accesses this web page; on logging into the system the controller has the following options as shown in figure 17:

- View Orders in the system

- Control events to be resolved in the system

- Future events list

- Exit 


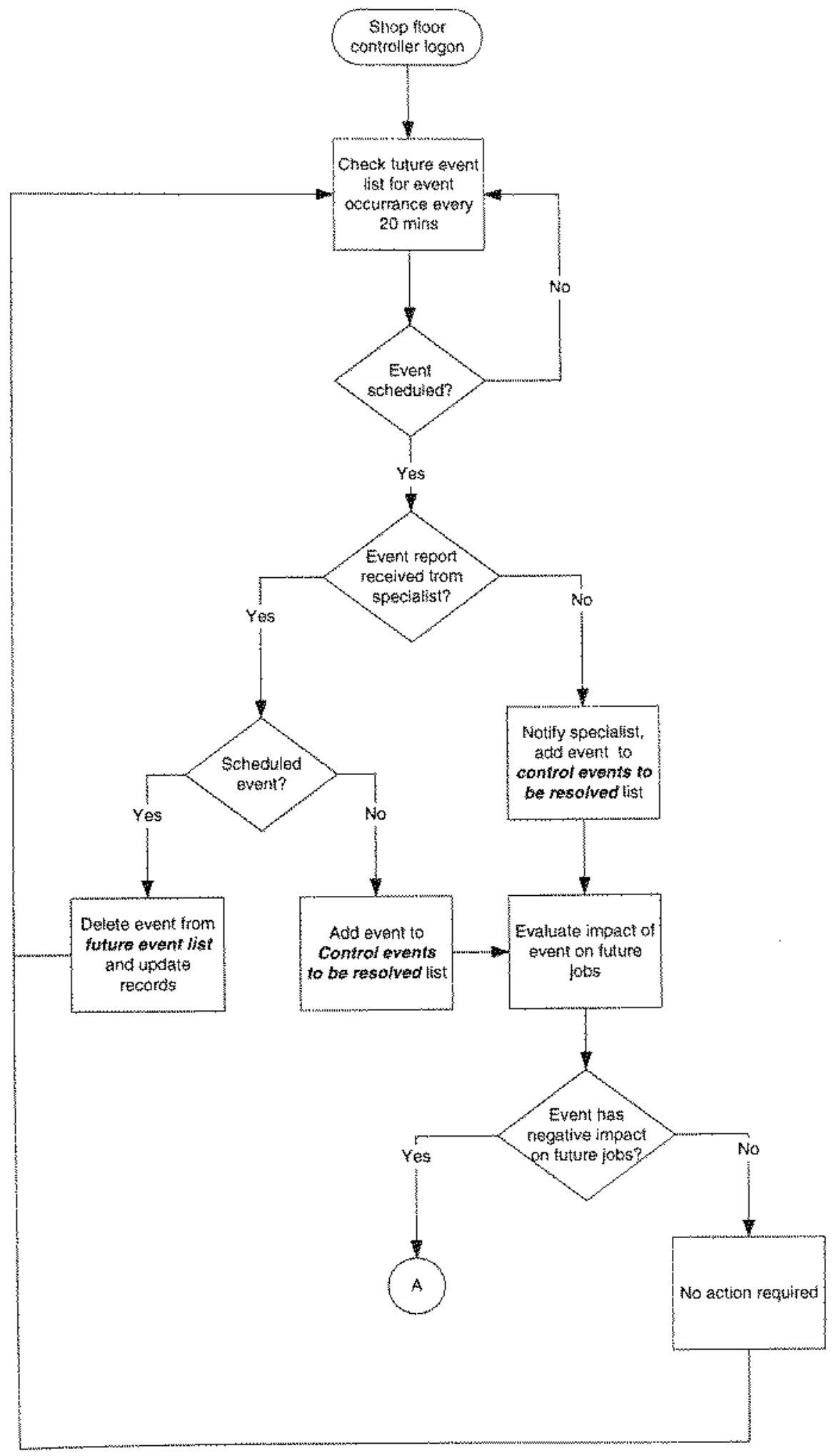

Figure 17a. Shop floor control system algorithm 


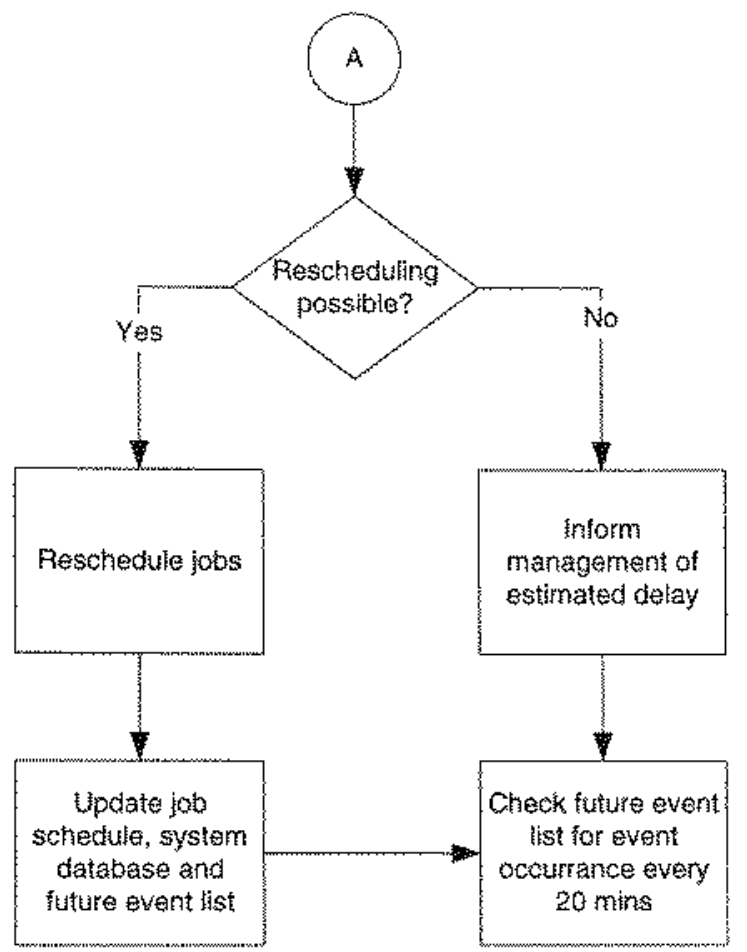

Figure 17b. Shop floor control system algorithm

View Job Orders in the SFCS: By selecting this link, the controller can see all the jobs that are under the purview of the shop floor control system. This list includes all those jobs that are currently being processed on the shop floor and the jobs that are scheduled and have been released to the shop floor, but the processing has not yet begun. All the relevant information like the order $\mathrm{D}$, name, job description, lot size, the date the job was released to the controller, the scheduled start and fintsh are listed on this page. The controller can check the detailed process plan and schedule for each job listed in the shop floor control system. (Figure 19) 


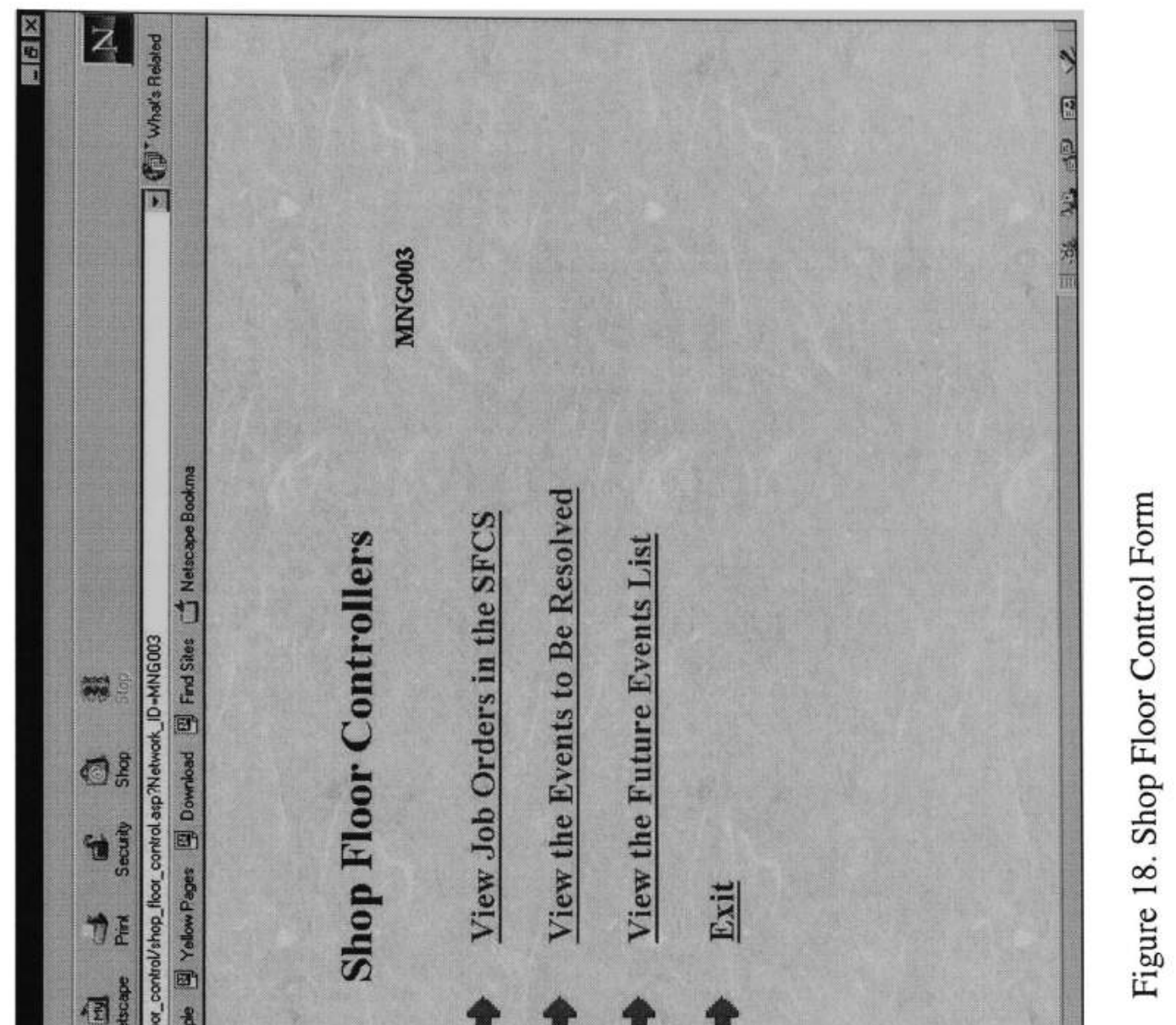




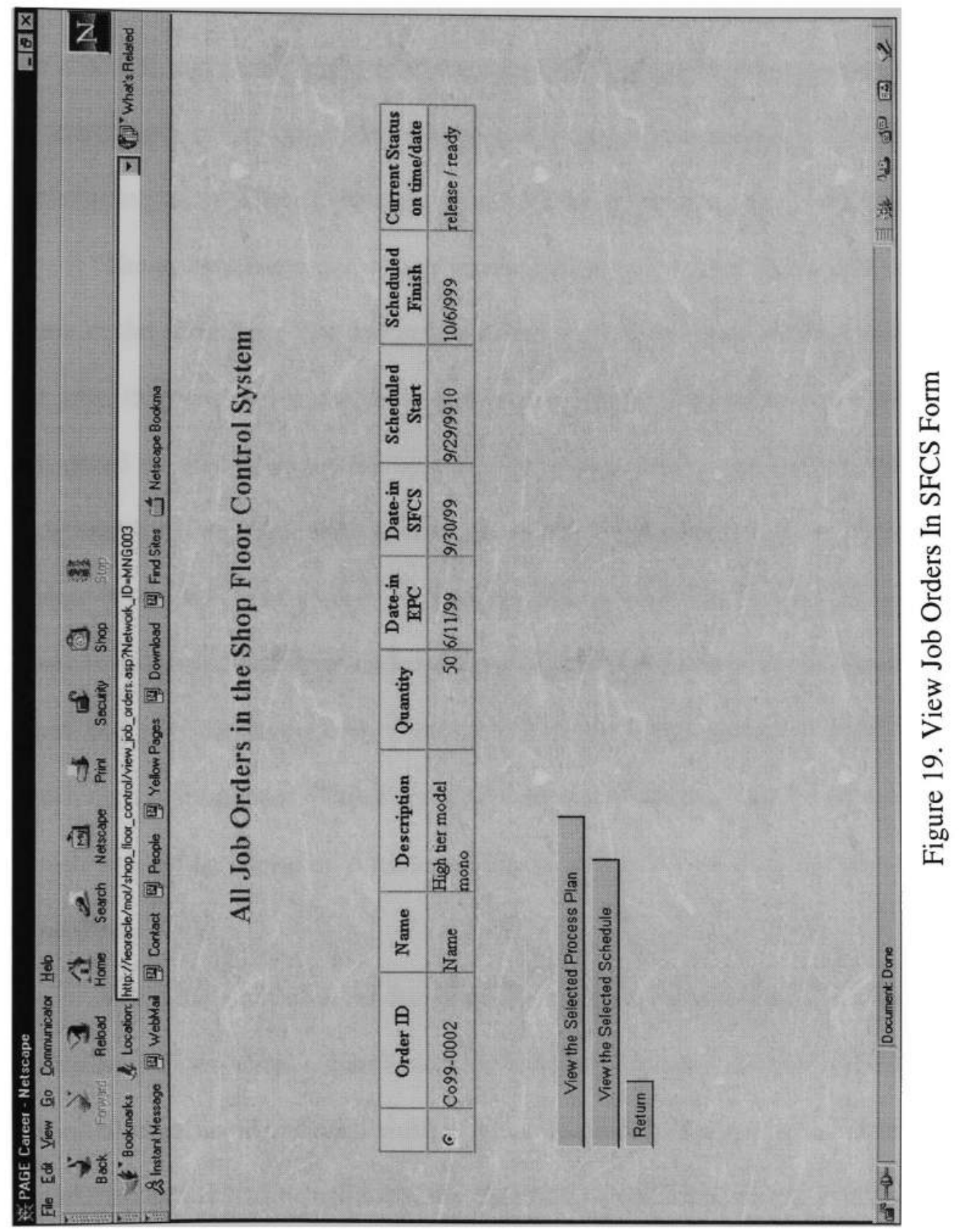


View the Events to Be Resolved: The list of events to be resolved is the problem events of the system. This web page as shown in figure 20 lists a table of all the jobs and events that have either defauted on the defined schedule and will most probably cause a delay in the schedule and hence might need the controller's attention. These events include, delay in startfinish of an operation, a specialist's absence, a machine breakdown, and an outsourcing delay. These events get recorded and appear in the list as described under:

The system has a complete record of all the operations that are scheduled to take place in the shop floor the job orders in the shop floor control table houses a list of all the jobs, their respective schedules and process plans). This is the future event list that is scheduled to take place in the system. The system has a sub routine written in the $\mathrm{C}$ programming language, which executes every 20 minutes and checks the system to update its records. The program checks the future event list in the database to see if an event is scheduled and then compares the "Time Now" or the "clock time" with the time when the next chronologically listed event in the future event list was/is scheduled to occur on the shop floor. This event could be either the notification of a scheduled stat /finish time of an operation or the notification of the arrival of an outsourced item to the shop floor.

When the specialist on the shop floor (or the outsourcing specialist) notifies the controller of an event (start/finish or outsourcing arrival) the system records the information received and then verifies that information (the specialist's event notification report) against the information in the database. If the information in the report and the records match, then the event is taken of the time line in the future event list. This 
indicates that the event was successfully completed at the scheduled time and no control actions are needed from the controller for those particular events.

If there is no information avalable on the status of an event from the shop floor, then the program activates another subroutine "Send_mail" which accesses the information pertaining to the related event from the database (information like the operation number, the job $\mathrm{D}$, the scheduled event occurrence time, the worker $\mathrm{DD}$, email address and name). An email is sent to the concerned specialist and logged in the database for tracking and record keeping purposes. At the same time the event also enters the control events to be resolved and the event is accorded a "new" status. This indicates that the system has just realized that the event has not occurred. If in the next cycle, the specialist does not respond to the email sent to him earlier, then the system resends the email and changes the status on the job to "specialist informed". This indicates that the job is delayed and requires the controller's attention.

This table lists the time when the delayed event was scheduled to occur and the time when the system detected the delay in the event. This gives the controller an indication of the degree by which the event is delayed. In addition to this information the table also lists the specialist and the work center associated with each job.

In case of the specialist absence/machine breakdown events, the specialists on the shop floor relay the information to the system and the status of the event on the control table is listed as "new" once the information has been received. The specialists are also required to provide the system with an estimated return/recovery time for the unavailable resource. This piece of information is added to the future event list, and then the system checks with the concerned user when the event next becomes scheduled. If the resource 
becomes available by then (this is notified by the specialist from the previous page) then the system takes this event from the future event list.

Each job delayed or resource becoming unavailable might potentially have an impact on successive jobs in the system. The controller needs to evaluate the impact of each such event and analyze the impact each delay might have on succeding jobs. The controller can choose each event and study its impact on other jobs. If there are any jobs that will definitely be delayed, then the controller has to take appropriate actions.

The controller can choose the event to be studied by clicking on the radio button against each event in the list, and viewing the impact that event delay might have on the schedule. This loads another page listing the details of the jobs affected. The information listed on the pages for the impact caused by each of the five event types are different. They are as under

- Jobs impacted by start/finish delay: The detail of the job actually delayed is provided on the header of the table. The table provides a comprehensive list of all the jobs that are affected by the above job being delayed and might potentially be delayed if no action is taken soon. The controller can view the overall schedule of all the affected jobs in a Gantt chart. The job causing the delay will be presented in red (or other different color, from the rest of the jobs). The controller can then decide whether to reschedule the job. Rescheduling the jobs involves the following options:

- Identifying an equivalent altemative resource (specialist/work center), which can perform the job at the scheduled time.

- Reschedule existing jobs (by shifting the jobs ahead or pushing them behind depending on the slack time avallability with each job operation) on that 
resource in such a manner so as to make this job fit into the original schedule, without actually delaying any of the other existing jobs.

- If neither of the above options is feasible, then the controller has to escalate the matter to management and change the status of the job to "pending" in the table. This is because the options with management involve making a decision pertaining to putting the job on overtime or if even that is not feasible then the management has to get back to the customer and find out if the estimated delay in the job is acceptable to them. If it is then, the job is rescheduled as per the new schedule and the system is back on track, since the job is within the specified due date as per the customer. Hence the sanctity of the schedule is maintained. (Figures 21 \& 22) 


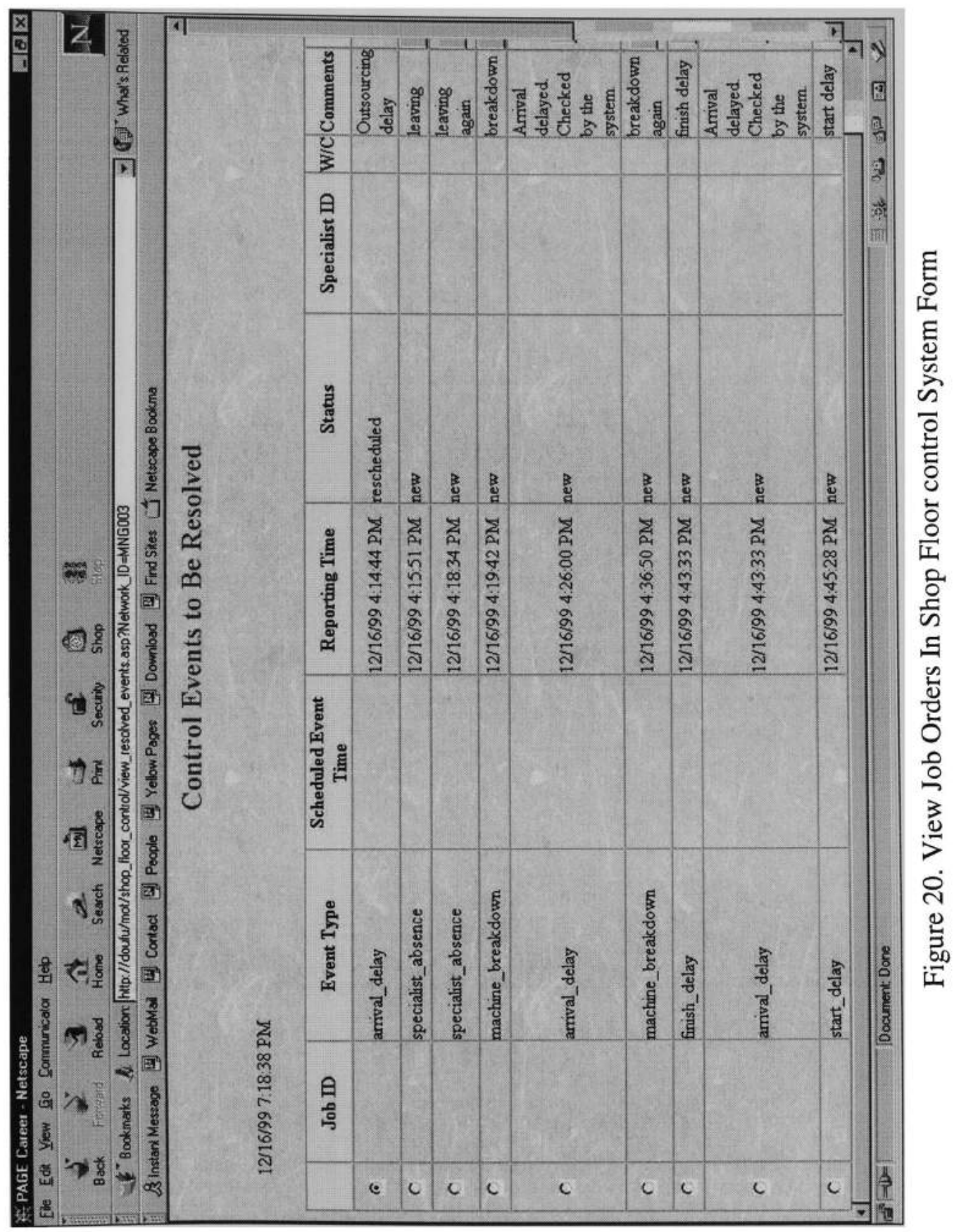




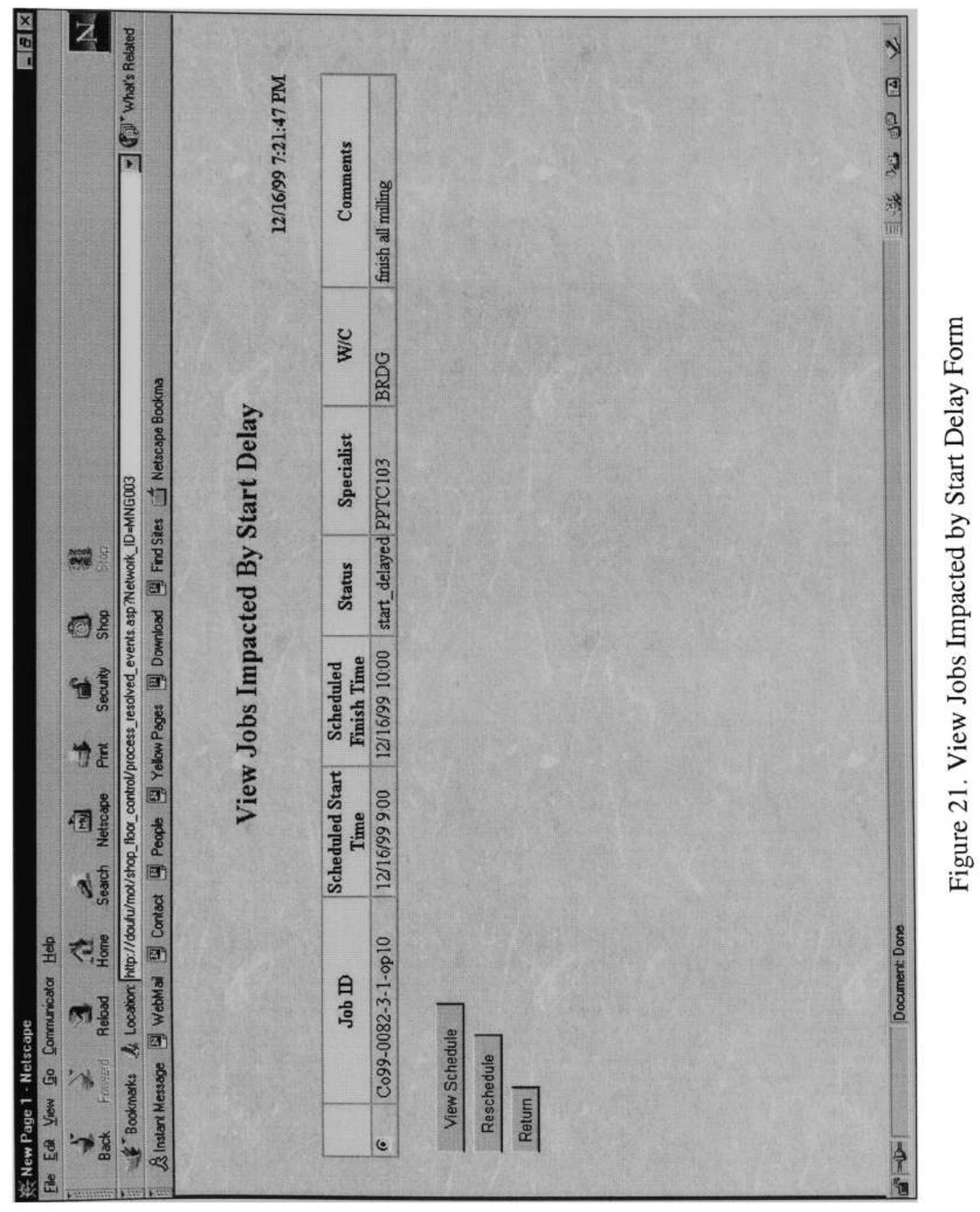




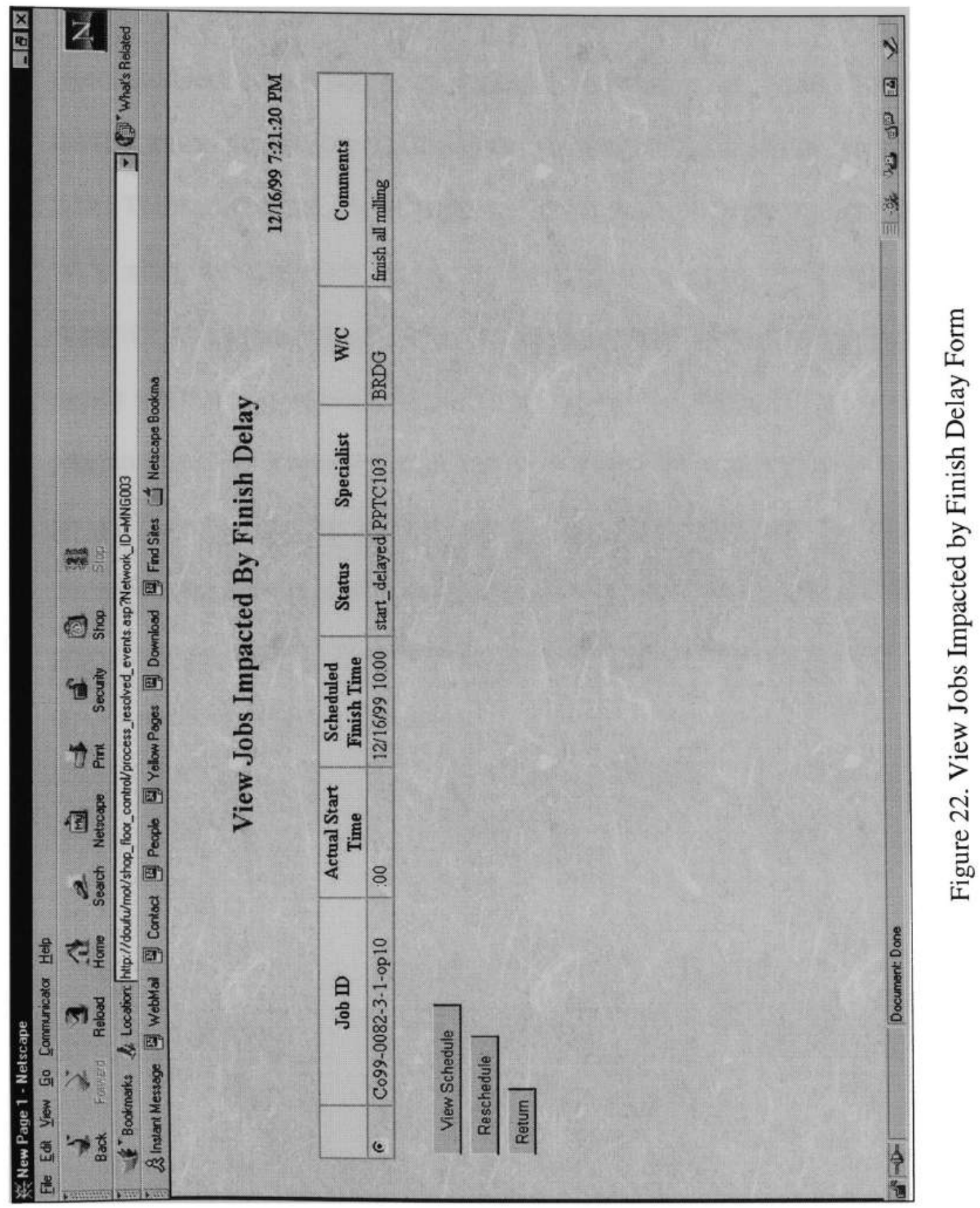


- Jobs impacted by resource (specialist/work center) unavallability: The detail of the resource that is unavailable is provided above the header of the table. The table lists the comprehensive list of jobs that are assigned to that resource. In case a resource (specialist/work center) becomes unavailable while processing a job, then that job is the first job on the list. The scheduled start and finish times of that job are listed in the table. The status of that job will show as "finish delayed" (since the start has already taken place as scheduled) all the remaining jobs will have their status as "start delayed". The controller can view the detail schedule of each job in this list and decide whether to reschedule the job or not. In case the scheduled stat of some of the jobs are after the estimated time when the resource becomes available, then there is no need to reschedule the job. Only those jobs, which are scheduled to be processed during the unavailable period, need to be considered for rescheduling, as they might potentially get delayed. The rescheduling of the jobs follows the same procedure as described above. (Figures $23 \& 24$ ) 


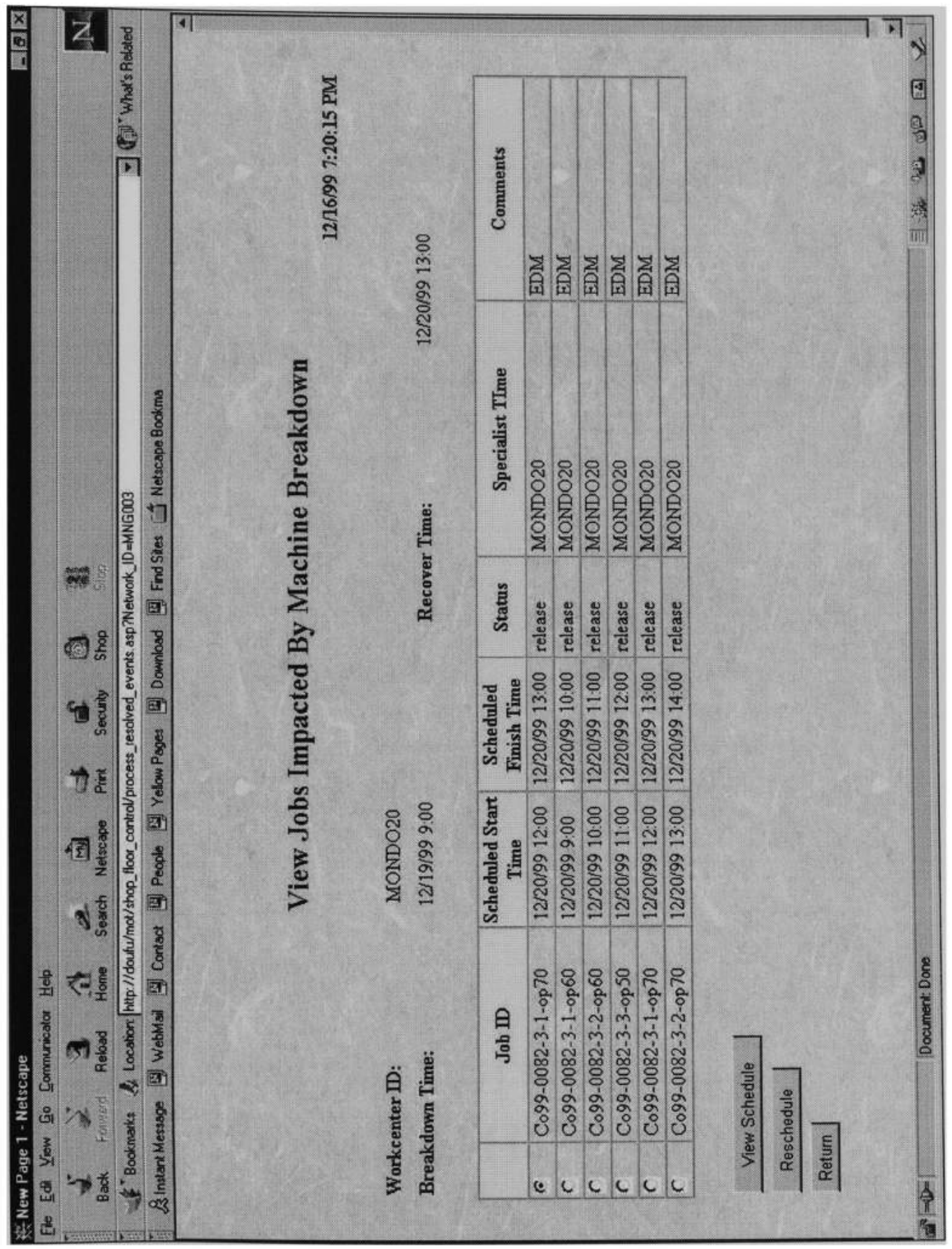

ह 


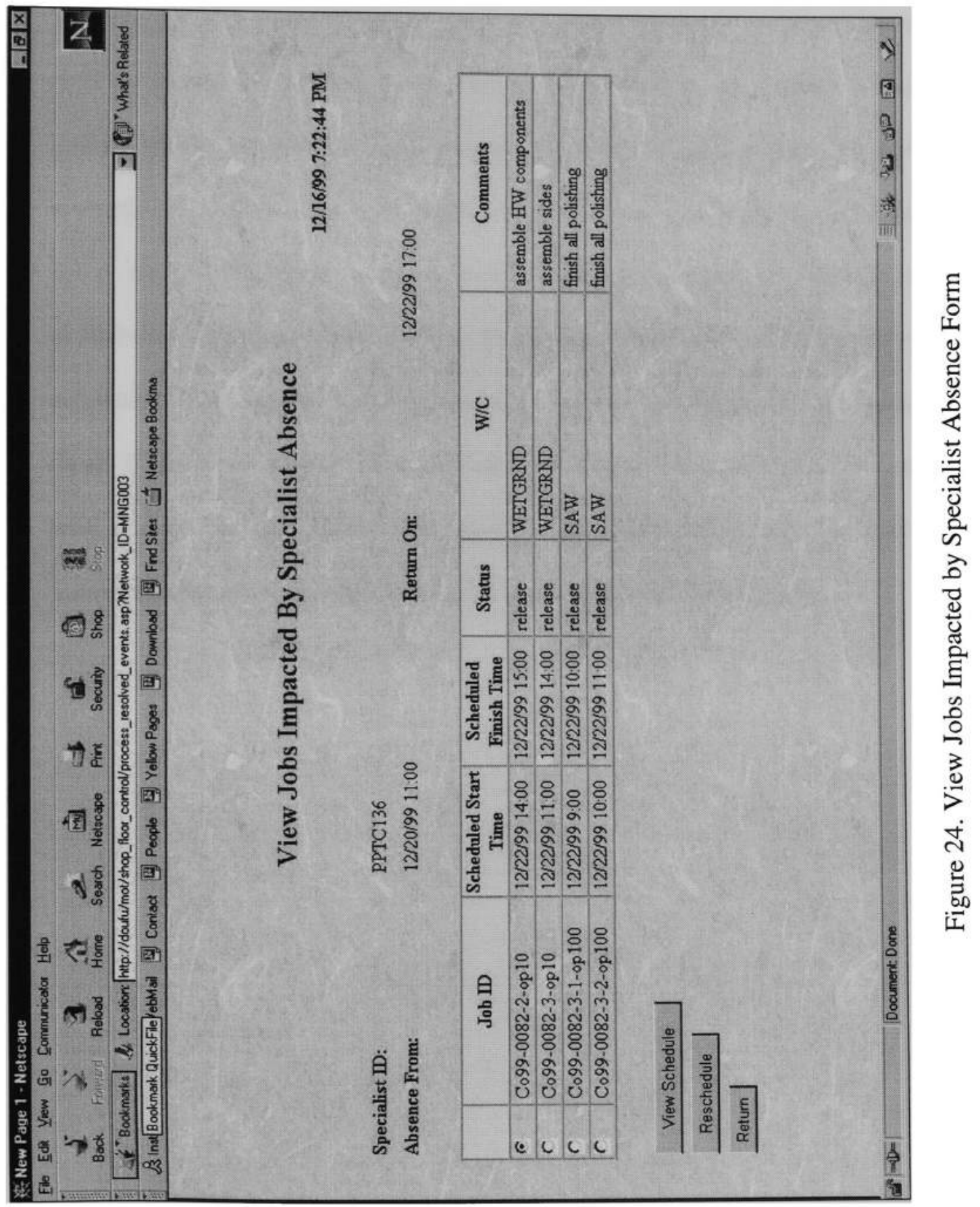


- Jobs impacted by outsourcing arrival delay: The details of the outsourced job like the internal order number and the new estimated arrival time is provided above the table. The jobs listed in the table are the job(s) that are constrained by the outsourced item. A delay in one sets off a domino effect in the other. The controller has to study the impact of the delayed start on the schedule and decide if the jobs have to be rescheduled. If they need to be rescheduled, then the procedure to be followed is as listed above. The jobs must necessarily be rescheduled to coincide with the availability of the outsourced item; this might sometimes conflict with other job schedules. The controller has to study each job individually and reschedule all of them. If there is a conflict in the schedule that cannot be sorted out, then the system will change the job status "pending" and the matter will be brought to the managements notice for appropriate decision making. (Figure 25) 


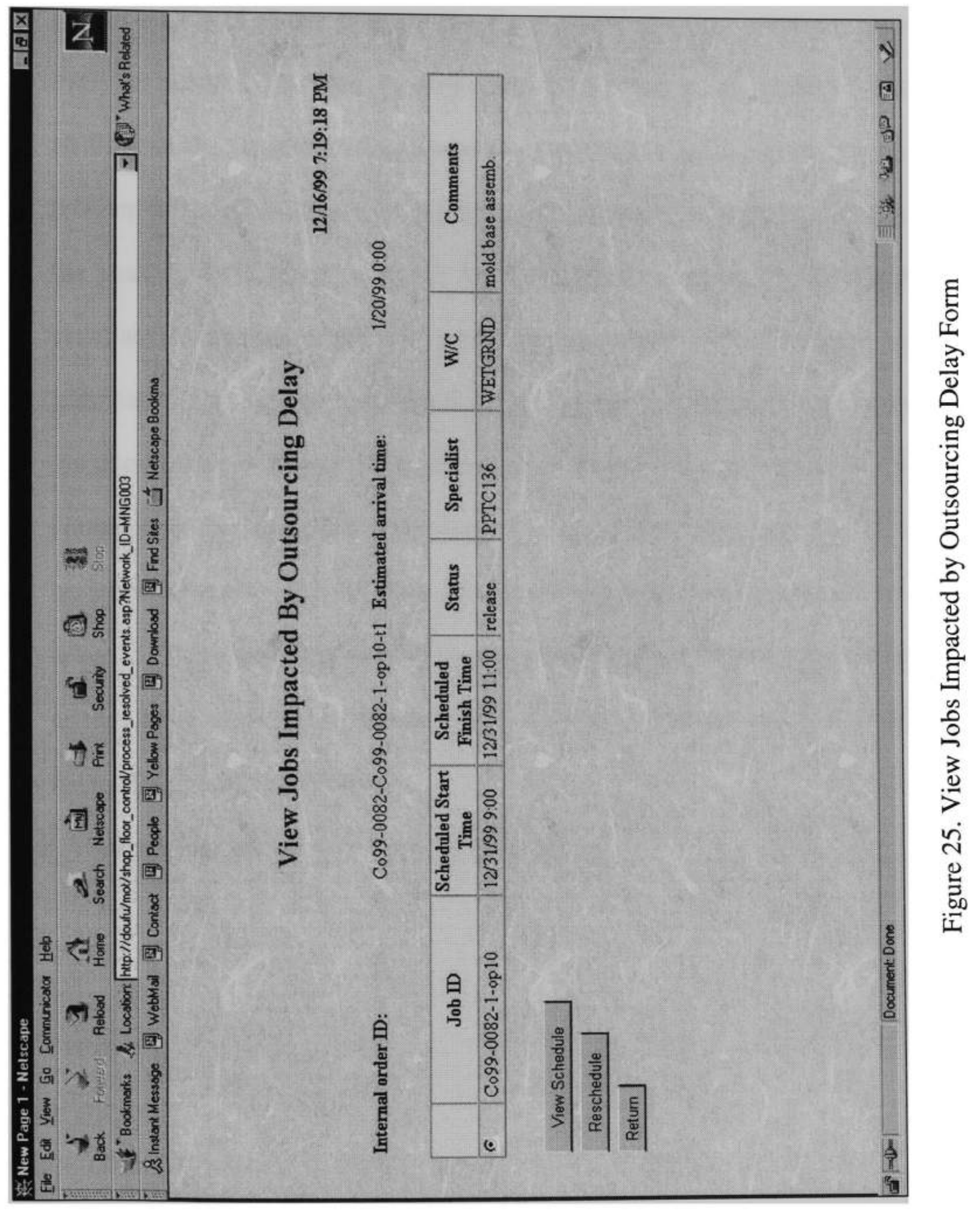


- Future Events List: Once a job has been scheduled, it enters enter the shop floor control system, the system records and logs all the operation start and finish times and creates a table of all the events called the future events list, which the system tracks every 20 minutes. This web page lists the detailed information on all the operations of all the jobs that are scheduled to take place on the shop floor control system. All the relevant information like the start times and finish times, along with the specialist and the work center is provided in this list. The controller can also check the constraints associated with each of the jobs in this list. A separate table listing the outsourced jobs due to arrive into the system is listed separately. The constraints for the jobs in the above table will necessarily match the jobs listed in the outsourcing list (if the constraint is an outsourced item). If a job does not have any constraint, its status will be listed as ready, if a job does have a constraint then its status will be listed as released. This means that some jobs are released but are not yet ready for processing as they have a constraint, which needs to be satisfied before processing can actually begin. (Figure 26a and 26b)

Exit: This link logs off the user from the system. 


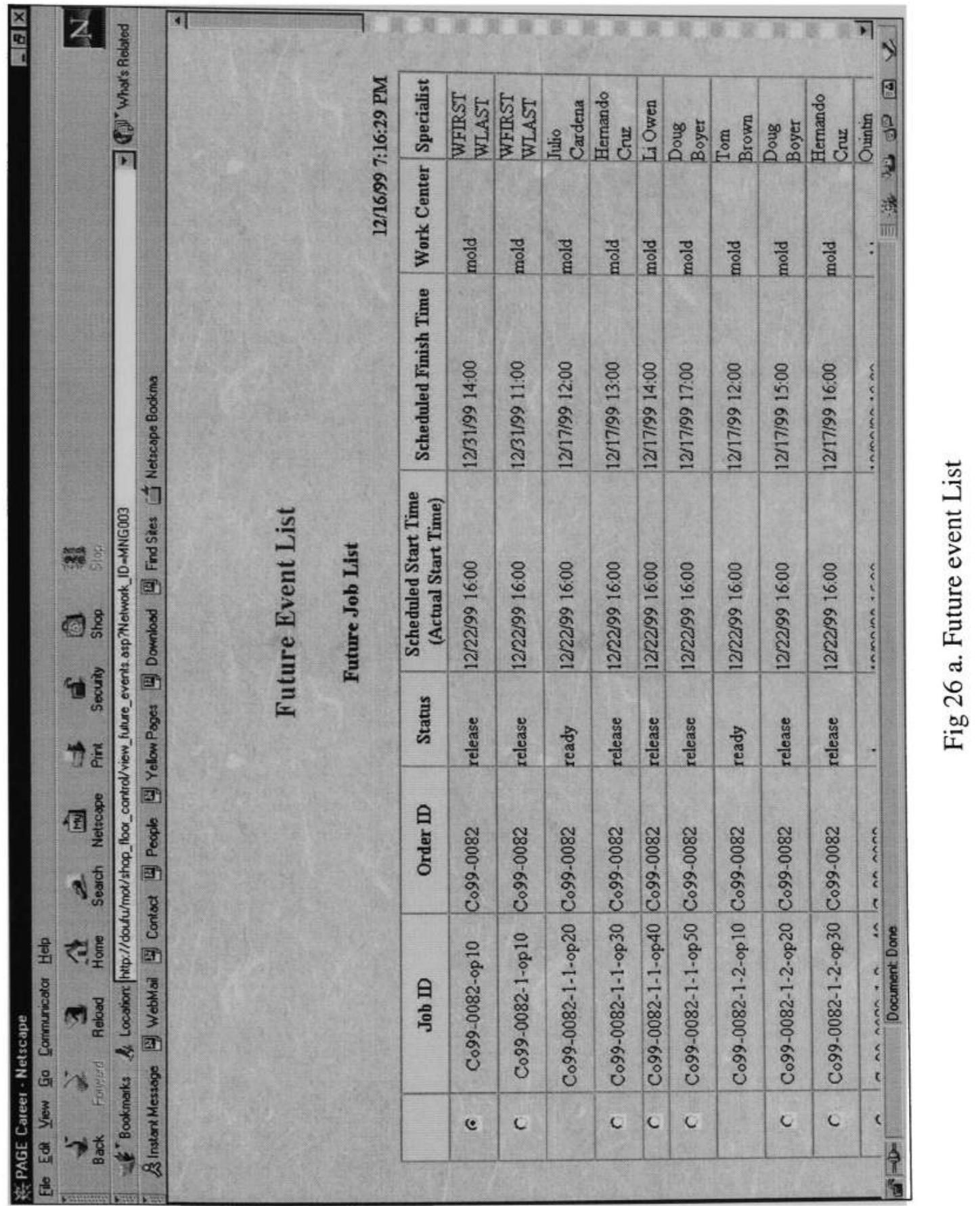




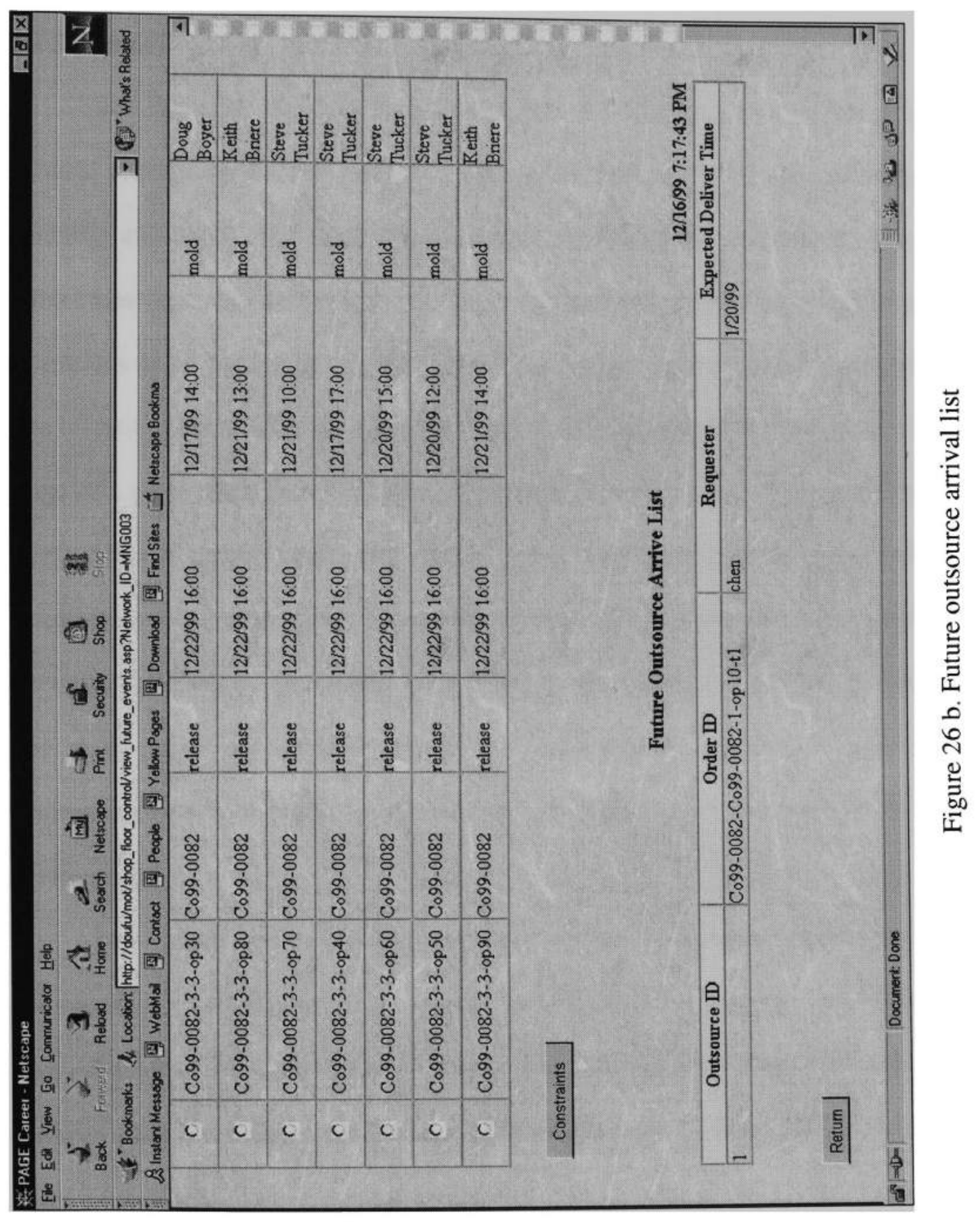




\section{Chapter Five}

\section{CONCLUSIONS}

\subsection{Summary}

In a dynamic job shop environment, it is a challenging task to ensure every job released to the shop floor in a dynamic job shop adheres to the schedule developed at the planning and scheduling stage. Random disturbances in the manufacturing operations often cause disruption in the schedule leading to jobs getting delayed, which in turn leads to a series of problems, all of which invariably have a cost factor associated with them. The effort to maintain the job schedule as per the developed plan at the process planning stage can, more often than not, offer a practical solution to most of the problems. There exist various algorithms and techniques, which perform shop floor control which provide an effective solution to some of the problems that arise in such scenarios, but there does not exist a mechanism which ensures that the system functions as per the developed plan. This study provides a viable solution to the problem by developing a shop floor control mechanism, which attempts to maintain the schedule feasibility in a dynamic job shop environment.

The system was designed to perform the shop floor control of jobs entering into the system with fixed process plan and schedule. Two event types were identified and seven distinct events were defined in the system. The control system was designed to be reactive while detecting a disturbance but proactive when rescheduling a delayed job. Once a job is scheduled it was released to the control system. All the job operations and related constraints were maintained on a time line, which the system would confirm with 
the users on the shop floor, either through reports sent by the users to the system or by requesting the users to confirm the status of the operation. When an operation does not occur as planned, the system notifies the controller and the controller evaluates the impact of the delay. If there is a negative impact, the delayed jobs are rescheduled using the same constraints, if alternate feasible schedules are not possible, then the matter is put forth to the management for further decision.

The shop floor control system implemented takes into account, the nature and type of disturbances that can possibly occur in the system at the operational level. All the jobs in the manufacturing system can be constantly monitored and tracked by both, the controller and the customer. The effort was to identify and isolate those particular control events that would have a detrimental effect on the schedule of the jobs on the shop floor. The system checks periodically to see which particular events have not been reported by the users on the shop floor and enables the controller to evaluate the impact a delay has on the overall schedule. In case the disturbance has a negative impact on the job schedule, the controller provides alternate solutions by rescheduling the job in the manufacturing system using the same constraints. In case a feasible solution is not available the system notifies the controller and the management makes a decision on whether the job should be taken into overtime, outsourced, or the customer's approval be sought to reschedule the job as per the estimated delay. In each of the cases, the effort is aimed at mantaining the job schedule as per the accepted due date.

The system is Internet based and provides easy access to all the users in the manufacturing environment and also provides the customer with ready access to all the jobs that are currently being processed at the center. The system enables the controller to 
ascertain the status of delayed jobs on a real time basis. The system is capable of rescheduling affected jobs by identifying equivalent resources and avalable times to ensure the schedule feasibility.

\subsection{Future research}

The system designed for the dynamic job shop environment is a highly capable and flexible system, but there still is some room for improvement in the existing design. There are potential areas in the system that can be made more intelligent than it actually is at the moment. One of the aspects that the system can incorporate is the ability to decide whether the jobs can be taken into over time when a feasible schedule is not available. The system can be designed to perform a thorough analysis of the overtime options, depending on the availability of the resources during the overtime, perform a complete cost analysis of the decision and then present a set of options to the management.

Another aspect that can be incorporated into the system is an intelligent learning module. Once the system is implemented, all the control issues can be recorded and housed in a database for future reference. When ever a new disturbance occurs the system can check with the knowledge base and learn how the disturbance was resolved and take decisions accordingly. Over a period of time the system can record all the different types of disturbances that have occurred in the system. By analyzing the information stored, the module can identify patterns in the occurrences of the various types of disturbances in the system. This knowledge can be translated into probabilities of event occurrences and taken into consideration when scheduling jobs, by incorporating the chance that a 
particular type of disturbance may occur while the job is being processed on the shop floor.

The control system can also aid in the management's decision-making process by providing various tools that perform a thorough quantitative analysis of the costs associated with each of the scheduling/rescheduling options available to the scheduler in the event of a disturbance occurring in the system. 


\section{References}

1. Aguirre O, Weston R, Martin F and Ajuria J.L, 1999, MCSARCH: An architecture for the development of manufacturing control systems in Inemational joumal of Production Economics, Vol. 62, pp. 45-59.

2. Ahmed I and Fisher W.W, 1993, Due Date Assignment, Job Order release, and Sequencing Interaction in Job Shop Scheduling in Decision Sciences Vol. 23, pp 633647.

3. Andersson N, 1997, Design Principles for open and reusable shop floor control software in Computers in Industry Vol.33, pp. $285+293$.

4. Baker D.A, 1998, A Survey of Factory Control Algorithms that can be Implemented in a Multi Agent Heterarchy: Dispatching, Scheduling and Pull in Journal of Manufacturing Systems, Vol.17, No.4, pp. 297-320.

5. Bauer A, Bowden R, Browne J, Duggan J and Lyons G, 1991, Shop Floor Control Systems - From design to implementation, Chapman \& Hall, first edition.

6. Belz R and Mertens P, 1996, Combining knowledge-based systems and simulation to solve rescheduling problems in Decision Support Systems, Vol.17, pp.141-157.

7. Bergamaschi D, Cigolini R, Perona M and Pottioli A, 1997, Order review and release strategies in a job shop environment: a review and a classification in International Journal of Production Research, Vol.35, No.2, pp. 399-420.

8. Bertrand J.W.M, 1983, The Effect of Workload dependent Due-Dates on Job Shop performance in Management Science, Vol.29, pp. 799-816.

9. Bilerg A and Alting.L, 1991, When Simulation takes Control in Joumal of Manufacturing Systems, Vol. 10, No.3, pp. 179-193. 
10. Blackstone J.H. Ir., Phillips D.T, Hogg G.L, 1982, A state of the art survey of dispatching rules for manufacturing job shop operations, in International Joumal of Production Research, Vol.20, No.1, pp.27-45.

11. Bongaerts.L, Jordan.P, Timeermans.P and Valckenaers.P, Wyns.J, 1997 , Evolutionary development in Shop Floor Control in Computers in Industry Vol.33, pp. 295-304.

12. Boucher T.O, and Jafari M.A, Design of a Factory Sequence Controller From a high Level System Specification, in Joumal of Manufacturing Systems, Vol.11, No.6, pp. $401-417$

13. Brussel H.V, Wyns J, Valkenaers P, Bongaerts L and Peeters P, 1998, Reference architecture for holonic manufacturing systems: PROSA in Computers in Industry, Vol. 37, pp. 255-274.

14. Chang, Fanmchang R, 1997, A study of Factors affecting Due-Date predictability in a Simulated Dynamic Job Shop in Journal of manufacturing Systems, Vol. 13, No. 6 , pp. 393-400.

15. Chen C.S, 1999, Design and implementation of an Internet-based Manufacturing Operation System for the Engineering Prototype Center at Motorola (white paper) March 1997.

16. Davis $M$ and O'Sullivan D, 1998, Communications technologies for the extended enterprise in Production Planning and Control, Vol.9, No.8, pp. 742-753.

17. Dilts D.M, Boyd N.P and Whorms H.H, 1991, The Evolution of Control Architectures for Automated Manufacturing Systems in Journal of Manufacturing Systems, October, Vol. 10, pp. 79-93. 
18. Eilon Samuel, Elements of Production Planning and Control, The Macmillan Company, third edition, 1969.

19. Hansen C.O, Laurensen R.P and Trostmann E, 1996, Real time control systems for one-of-a-kind production based on state modelling in Production Planning \& Control, Vol. 9, No.5, pp.435-447.

20. Holthaus $O$ and Rajendran $C, 1997$, Efficient dispatching rules for scheduling in a job shop in Intemational Joumal of Production Economics, Vol. 48, pp. 87-105.

21. Hye P.K and Joel F, 1999, Virtual Enterprise - Information system and Networking Solution in Computers and Industrial Engineering, Vol.37, pp.441-444.

22. Kappelhoff $\mathrm{R}, 1998$, Integration of ERP to the final control elements in ISA Transactions, Vol. 36 , pp. 229-238.

23. Karacal S.C, 1998, Simulation of Hierarchical Manufacturing in Computers Industrial Engineering, Vol.35, Nos. 1-2, pp. 339-342.

24. Kim K.H, Song J.Y and Wang K.H, 1997, A Negotiation Based Scheduling for tems with Flexible process Plans in Computers in Industrial Engineering, Vol. 33, Nos. 34 , pp. 785-788.

25. Land M.J and Gaalman G.J.C, 1998, The Performance of Workload Control Concepts in Job Shops: Improving the Release method in International Joumal of Production Economics, Vol. 56-57, pp. 347-364.

26. Lee S, Wysk R.A, and Smith J.S, 1995, Process Planning interface for a shop floor control architecture for computer integrated manufacturing in Intemational Joumal of Production Research Vol.33, no.9, pp. 2415-2435. 
27. Lin G. Y.J and Solberg I.J, 1992, Integrated Shop Floor using Autonomous Agents in IIE Transaction Vol.3, Number 3, July pp. 57-71.

28. Little D and Yusuf Y.Y, 1997, Manufacturing Control Systems -.. Moving Towards the Enterprise Model in $5^{\text {th }}$ International Conference on FACTORY 2000, 2-4 April 1997, Conference publication No. 435, pp. 388-394.

29. Maglica R, 1997, Improving the PAC shop floor control architecture to better support implementation in Computers in Industry, Vol.33, pp. 317-322.

30. Manivannan S. and Banks J, 1992, Design of a Knowledge-based on-line Simulations System to Control a Manufacturing shop floor in IIE Transaction Vol.24, Number 3, July pp. $72-83$.

31. Melynk S.A and Ragatz G.L, 1989, Order review/release: research issues and perspectives in Intemational Journal of production Research, Vol.27, No.7, pp.10811096.

32. Monostori L, Szelke E, and Kadar B, 1998, Management of Changes and Disturbances in manufacturing Systems in Annual Reviews in Control Vol.22, pp. 8597.

33. Ng J.K.C and IP W.H, 1998, The Strategic Design and Development of ERP and RTMS in Computers in Industrial Engineering, Vol. 34, No. 4, pp. 777-791.

34. Perona $\mathrm{M}$ and Portioli $\mathrm{A}, 1998$, The Impact of Parameters Setting in Load Oriented Manufacturing Control in International Journal of Production Economics, Vol. 55, pp. 133-142. 
35. Phillipoom P.R. Mahotra M.K, and Jensen J.B, 1993, An Evaluation of Capacity Sensitive Order Review and Release Procedures in Job Shops in Decision Sciences, Vol.24, No.6, pp.1109-1133.

36. Ragatz G.L and Mabert V.A, 1988, An Evaluation of Order Release Mechanisms in a Job-Shop Environment in Decision Sciences, Vol.19, pp167-189.

37. Rovithakis G.A, Gaganis V.I, Perrakis S.E and Christodoulou M.A, 1999, Real-Time control of manufacturing cells using dynamic neural networks in Automatica, Vol.35, pp. 139-149.

38. Saleh A, Odrey N.G and Wilson G.R, Design and Algorithmic Implementation of a Real-time Controller for a manufacturing cell in Design, Analysis and Controt of Manufacturing Control PED Vol. 53 Page $203-229$.

39. Smith J.S, Hobrecht W.C and Joshi S.B, 1996, A Shop Floor Control Architecture for Computer Integrated Manufacturing in IIE Transactions, Vol. 28, pp. 783-794.

40. Tatsiopoulos I.P, 1997, An Orders Release Reference Model as a Link between Production Management and Shop Floor Control Software in Computers in Industry, Vol. 33, pp. 335-344.

41. Tharumarajah A and Bemelman R, 1997, Approaches and Issues in Scheduling a distributed shop-floor environment in Computers in Industry, Vol.34, pp. 95-109.

42. Tu Y, 1997, Production Planning and Control in a Virtual One-of-a-Kind Production Company in Computers in Industry, Vol. 34, pp. 271-283.

43. Wright D.T and Burns N.D, 1997, Cellular Green-Teams in global network organization in International Joumal of Production Economics, Vol.52, pp.291-303. 
44. Yurtsever T and Pierce N.G, 1998, Computerized Manufacturing Monitoring and Dispatch System in Computers in Industrial Engineering, Vol. 35, Nos. 1-2, pp. $137-$ 140.

45. Zamai E, Chaillet-Subias A, and Combacau M, 1998, An Architecture for control and monitoring of discrete event systems in Computers in Industry, Vol.36, pp. 95-100.

46. Zwegers A.J.R, Fang S.G and Henk-Jan Pels, 1997, Evaluation of Architecture design with CIMOSA in Computers in Industry, Vol.34, pp. 187-200. 